\title{
FACEBOOK WRITTEN LEVANTINE VERNACULAR LANGUAGES
}

\author{
Dua'a Abu Elhij'a*
}

\subsection{Introduction}

Over the last fifteen years, in every Arabic-speaking country, young Arabic speakers have begun to write their spoken language in electronic media, such as Facebook, MSN Messenger, and so on. A few typical examples, taken from Facebook in the Levant are as follows:

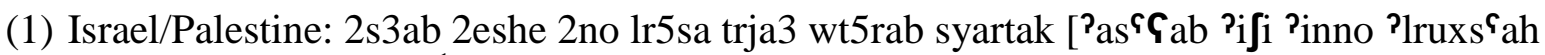
$\operatorname{trd} 3 a$ G w xrab sjartak $]^{1}$ ("“the hardest thing is to get back your driving license, but then have your car break down"“).

(2) Lebanon: rah yontor ktiiir w ma haychoufo [rah jont ${ }^{\varsigma}$ or kteer w maahajJufo] ("'he will wait for a long time, and he will not see him"').

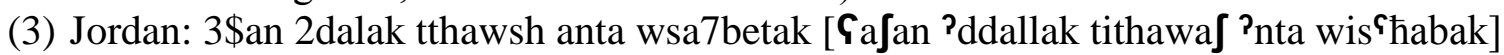
("“so that you keep fighting with your friends"').

This new way of writing is a radical deviation from the traditional norm of writing the classical language - as well as what is commonly referred to as Modern Standard Arabic. In this study, I am going to present this phenomenon in the Levant - Jordan, Lebanon, and Israel/Palestine. ${ }^{2}$ This study is the first of its kind using variationist methodology. Until now, this methodology, first developed by William Labov (see Labov, 1963, 1966, 1972a, b, 1973), has been generally used to analyze spoken language; there have been some studies of written language, although the great majority of these have analyzed syntactic and lexical variation rather than orthographic variation, because of the effect of standardization on orthography (e.g. Pettersson 1999:101; Poussa 1999:29).

This phenomenon of writing CMC (computer-mediated communication) in colloquial language is common worldwide. December (1996, cited in Romiszowski and Mason 2004: 397) defines $\mathrm{CMC}$ as "the process by which people create, exchange, and perceive information using networked telecommunications systems that facilitate encoding, transmitting, and decoding messages." Jones (1995, cited in Romiszowski and Mason 2004: 397) states that "CMC, of course, is not just a tool; It is at once technology, medium, and engine of social relations. It not only structures social relations, it is the space within which the relations occur and the tool that individuals use to enter that space." Along with the progress of technology and electronic devices, especially computers, new ways and systems of writing have appeared, most significantly in the case of diglossic languages such as Arabic (Ferguson, 1959). The registers into which Arabic is divided are, on the one hand, a single "high" language ordinarily referred to as Fusћa, which is normally written, and on the other hand, some two-dozen "low" languages called Amiyyas, which are normally only spoken and seldom formally written. Spoken Arabic has many different dialects, which, if ever written at all, are often written exclusively in Arabic letters, and only to convey popular poetry and newspaper comic strips, but seldom for the purpose of serious literary work (Garra, 2007). With the advent of CMC, however, various systems of writing spoken Arabic, using Arabic script, Latin script, and (in Israel) Hebrew script, have begun to develop for use on electronic devices, especially computers.

\footnotetext{
${ }^{1}$ Squarebrackets [ ] indicate the pronunciation according to the International PhoneticAlphabet used by linguists.

${ }^{2}$ Syria is excluded since on Facebook, Arabic script is used a whole lot more than Latin.
} 
In this study, I investigate the writing of the consonants, ${ }^{3}$ the definite article, and negation, using Latin script, on Facebook, by Levantine Arabic speakers. The sample data is that of the written spoken language, which varies markedly from one person to another depending on different social aspects, such as age, gender, and socioeconomic status (see Hudson, 1996; Trudgill and Cheshire 1998; Wardhaugh, 1986; and Weinreich, Labov, and Herzog, 1968).

\subsection{Electronic Writing}

In the last few decades, along with the progress in technology and electronic devices, especially computers, a general worldwide pattern has begun to develop among young people writing emails, SMS, chat messages, and Facebook entries in their colloquial language (local dialects) (Palfreyman\& Al-Khalil, 2003).The tendency to write electronically in colloquial language has naturally had a particularly strong effect in diglossic situations, such as Arabic, where the very wide gap between the spoken dialects and the traditional written language has meant that writing the spoken language often necessitates essentially inventing a new writing system, to which I will be referring here as Electronic Amiyya (EA).

This linguistic development is now occurring in many languages in the world, and Arabic is just one example. Computer savvy Chinese youth for instance are also deviating from the standard Chinese writing system by mixing spoken and written language features in order to facilitate the written use of oral dialects on the Internet (Liu, 2011). In Japan, young Japanese employ colloquial language online, for example, by using eccentric spelling, which reproduces actual articulation in the typed message. One example of this is that in place of the conventional spelling of ありがとう arigatou “thank you,” youngsters use ありがと二 arigatoo (the difference is underlined) (Nishimura, 2003). In this example, we see that young people prefer to use the symbol - , which is used to lengthen any preceding vowel, rather than the prescriptive usage, which specifies the particular vowel.

To use an example from the Arabic-speaking world, in Egypt people speak the Egyptian dialect and ordinarily write in Fusha (Classical Arabic). However, Egyptian Arabic (see Al-Tonsi, 1980 ) is not only the spoken language in Egypt; it is also often written in poems, comic strips, and novels. When using the Internet, many educated young Egyptians use English in their formal online communication and emails, and Latinized spoken Egyptian in their informal emails and online chats (Warschauer, et al., 2002).

In short, electronic usage of written colloquial language is a worldwide phenomenon, of which EA is just one example. However, the effect of this phenomenon is particularly significant as regards diglossic languages.

\subsection{The Arabic Language: Some Background}

Arabic is a Semitic language, whose domain of usage extends from the Atlantic Ocean in the

\footnotetext{
${ }^{3}$ In spite of their significance, I did not include vowels in my study for many reasons. One is that vowels are much more complicated, non-standardized, and their usage changes radically from one person to another. Thus, vowels need a very long and elaborate study in their own right.
} 
west, to the Arabian Sea in the east, and from the Mediterranean Sea in the north, to the northern Sahara in the south. It spreads through two continents and is used in about 25 countries having an approximate population of 325 million people. It is ranked in fifth place among the languages of the world based on the number of users, its socio-literary prestige, and its geographic spread (Weber, 1997, cited in, Palfreyman,D. \& Al-Khalil, M., 2003.) Therefore, like English, Arabic can be considered a "world language."

\subsection{Arabic Dialects}

According to Fischer and Jastrow (2000), Arabic dialects ${ }^{4}$ are divided into five major groups. ${ }^{5}$ Each group comprises macro and micro dialects, which are distinguished in a variety of waysphonologically, phonotactically, morphologically, syntactically, lexically, and so on. One major dialectal group is the Syrian-Palestinian, or the Levantine group, which consists of the dialects of Syria, Lebanon, Palestine, and the northern and northwestern parts of Jordan. This is a very large group that includes many different micro-dialects. In urban Levantine dialects, for instance, the letter thaa' is pronounced [t] or [s], and the letter dhal is pronounced [d] or [z]. In Israel/Palestine, some letters can be pronounced in some places as pharyngeal, and in other places as less or non-pharyngeal. For instance, the $q a f^{6}$ can be pronounced as $\left.[\mathrm{k}],{ }^{2}\right]{ }^{7}[\mathrm{~g}]$ and [q], and the letter jeem has two pronunciations: [dz] and [3]..$^{8}$ The letter Dhaa $/ \mathrm{d}^{\varsigma} /{ }^{9}$ has several pronunciations according to the area in which the speaker lives and depending on the wordthat is to say, this letter can have a certain pronunciation in one word and a different pronunciation in another. For example, it can be pronounced as $[z]$ in the female name [ðৎarīfi],

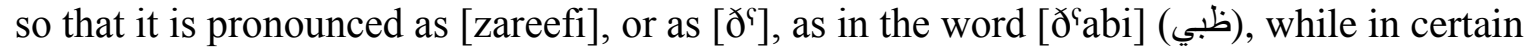
cases it is pronounced as $\left[{ }^{\varsigma}\right]$, especially in words that are originally from Fusha. The letter

${ }^{4}$ Linguists have shown that there is a dialect that characterizes every individual person, which is called an idiolect, and in this sense the number of idiolects in a language equals the numbers of the speakers of the language (Translated from: Freha 1989: 86).

${ }^{5}$ According to Freha (1989: 86-89) there are three major reasons for the existence of a wide variety of Arabic dialects. The first is the individual differences in voice, intonation, stress, vocabulary choice, and sentence structure. The second reason is the huge geographical landscape of the Arabic-speaking world, which leads to social and language divisions. The third reason is the influence of other languages on the homeland language, for instance, the influence of Persian and Aramaic on Arabic. As we will see, letters in spoken Arabic are pronounced differently depending on the dialect, and social status, group, sex, and origin of the speaker.

${ }^{6}$ According to Fischer and Jastrow (2000: 167), the qaf is pronounced as a glottal stop in the urban areas of Lebanon, Israel, Jordan, Syria and in the rural areas around Damascus, as well. It is pronounced [q] in Lebanon and the central and the northern parts of Syria. In Central Israel it is pronounced [k] and the letter kaf in these places is usually pronounced [t]]. See also (Bergsträsser 1915, Map 4; Blanc 1953:70; Bauer 1926:4; Driver 1925:10).

7 There are two explanations about the origin of $q a f$ pronounced as a glottal stop: The first is that it is an ancient phenomenon in some Arab tribes to pronounce qaf as a glottal stop. The second is that the qaf was sometimes pronounced with some glottalization, and in the long run the original sound of qaf faded and the glottal stop remained (see: Kamal Bisher, 2000: 283-284).

${ }^{8}$ In Northern Syria and Israel-Jordan, jeem is pronounced [d3]; however, in the urban areas of Israel-Jordan it is pronounced [3]. This phenomenon of [3] originated in the urban areas in Central Syria and Lebanon, and it spread to the other urban areas nearby (Fischer and Jastrow 2000: 167). However, Levin (1994:19) reports [3] for Jerusalem. See also Bergsträsser 1915, Map 2; Blanc 1953:66; Palva 1984:361-363.

${ }^{9}$ Linguists use slashes // to mark a phoneme, the abstract conception of a sound which can be pronounced different in different dialects and in different linguistic environments. 
$\mathrm{D}^{\varsigma}$ aad $/ \mathrm{d}^{\varsigma} /$ is usually pronounced $\left[\mathrm{\partial}^{\varsigma}\right]$ in rural areas and $\left[\mathrm{d}^{\varsigma}\right]$ or $[\mathrm{d}]$ in urban areas. Finally, the letter $t^{\uparrow} a a^{\prime}$ is generally pronounced [ $\left.\mathrm{t}^{\varsigma}\right]$ by villagers and [t] by urban people.

\subsection{Electronic Amiyya}

Electronic Amiyya ${ }^{10}$ (EA) is the electronic written language used mainly by teenagers and young adults in the Arabic-speaking world. EA emerged because as the world gradually turned into a village where people could communicate regardless of the distances that separated them, young adults felt a strong need to be able to communicate in their own spoken dialects via electronic devices (computers and telephone texting) and through social network sites such as Facebook. Moreover, "since early planners of the Internet were generally Americans, and were implicitly thinking only about how to facilitate communication in English, they did not anticipate the problems that might arise when speakers of other languages tried to communicate online" (Danet and Herring, 2003:1). In fact, in the 1990s, 80\% of international web sites were in English (Cyberspeech, 1997). In the last decade, however, the number of non-English websites has exceeded that of English sites (Crystal, 2001), so that it has become necessary to write languages other than English colloquially on the Internet. As a result, these other languages have adopted certain features to fit the electronic usages and overcome the barriers to electronic communication. Arabic and its variants belong to these languages, and thus EA came into being.

Since many phonemes are pronounced differently in different places throughout the Arabicspeaking world, some of the variation in EA is the result of variation in the spoken dialects; while some is the result of different writing conventions developing in different places-for example, [ $\left.\int\right]$ is written as $\left\langle\mathrm{sh}>^{11}\right.$ in the Gulf, Jordan, Israel/Palestine and Egypt but as <ch> in North Africa (we will see that both forms are used in Lebanon).

It is crucial to understand that EA usage is affected by various sociolinguistic factors, including prestige, gender, and dialectal variation; particularly between urban and rural speech, some of which factors overlap - for example, urban females are particularly associated with prestigious speech. Ibrahim (1986), in his article "Standard and Prestige Language: A Problem in Arabic Sociolinguistics," discusses these issues in detail. He presents an explanation of why women are more concerned with prestige than men: "women have such an inferior social position and are, therefore, less secure socially and psychologically than men, that they are expected to 'behave themselves' linguistically" (Ibrahim 1986: 123). This statement strongly supports the results of sociolinguistic studies of other languages, which indicate that in many communities women are usually the innovators of changes in speech (see Labov, 1982). We will see that the same factors affect EA usage; for example, we will see that rural women in Israel and Jordan speak one dialect and write in another.

\subsubsection{The Problematic Sounds of Levantine Arabic when Written with Latin Letters}

Ornan (2003:3) explains that "[t]he main difficulty in adapting an alphabet that is not the language's original one is that the target letters do not always supply or are not always suited to

\footnotetext{
${ }^{10}$ Amiyya is the Arabic name for the Arabic spoken language. Amiyya should actually be Amiyyaat (in the plural) and includes very many different dialects.

${ }^{11}$ The symbols $<>$ are used by linguists to indicate symbols that non-linguists use when writing.
} 
the store of sounds and phonemes of the converted language." Therefore, since Arabic includes some sounds that do not have regular correspondences in the Latin script, speakers of Arabic dialects writing their language in Latin script have had no choice but to adapt symbols that are not actual alphabetic letters, particularly numerals, to represent them.

Levantine youngsters use many strategies when inventing symbols:

1. Exploiting phonetic similarities between the Arabic and Latin sound, for example, the Arabic letter $t a a^{\prime}$, written as <t>, etc. (Garra, 2007: 65).

2. Exploiting the visual/orthographic similarity between some Arabic phonemes and numerals (Garra, 2007: 66); for example, the number <3> stands for the Arabic letter $\langle\varepsilon\rangle / \mathcal{G} /$. Similar examples are the letter $t^{\uparrow}$ aa $/ t^{\uparrow} /$, which can be written as $\langle 6\rangle$, and the use of the number $\langle 2\rangle$, which resembles the Arabic $\left\langle\boldsymbol{\varepsilon}\right.$, to write the glottal stop [?]. ${ }^{12}$

3. Using the apostrophe as an Arabic diacritic. For instance, the letter ghain / $/ \mathrm{/}$ in Arabic is represented in EA as $\langle 3$ ' $\rangle$ or $\langle$ ' 3$\rangle$. The apostrophe stands for the diacritic above $\langle\dot{\varepsilon}\rangle$. In addition, the $\langle 7\rangle$ is used to represent $/ x /$, written is Arabic as $\langle\dot{\tau}\rangle$.

4. Exploiting visual similarity to a Latin letter: For example in some areas where it is pronounced $[\mathrm{g}]$, the numeral $\langle 8\rangle$ can be used to represent the $q a f$.

5. Using digraphs, either borrowed (from English or French e.g., $\langle$ sh $\rangle \mid\langle\mathrm{ch}\rangle$ ) or invented (e.g., $\langle\mathrm{gh}>$ for $/ \mathrm{s} /,<\mathrm{kh}>$ for $/ \mathrm{x} /$ ), particularly to write proper names. To represent $/ \mathrm{g} /$ in Arabic-speaking countries where people are influenced by English, people use <sh>, while in countries which are influenced by French, such as Lebanon and North African countries, they tend to use <ch>.

6. In some cases it is hard to discover the motivation behind choosing one numeral or symbol and not another (Garra, 2007:67); for example, the use of $\langle \$\rangle$ for sheen in Jordan, $<8>$ for ghain in Lebanon and the Triangle in Israel/Palestine, and $\langle 5\rangle$ for the voiceless uvular fricative used to represent the phoneme $\mid x /$, which was initiated in the Gulf. The <5> might be taken from the Arabic word xamsa, which starts with the phoneme $/ x$ / and means five (Garra, 2007: 68, Yaghan, 2008: 44).

\subsection{Methodology}

In the following sections I will discuss variation in Levantine EA. Between August 2010 and July 2011, I collected data from the Levant. ${ }^{13}$ I gathered data from Facebook by adding as many friends as possible.

The next step was to read as many comments as possible and to examine my contacts' lists of friends to ensure that my contacts were actually from the place they listed in their profiles. I usually looked for surnames, since in certain places, surnames are an indication of a persons' original domicile and religion, and also indicate whether a person is Bedouin, as in the case of Arabs from Jordan. I read the comments to assess whether the writer actually wrote in the dialect of the town shown in his/her profile.

After collecting the data and saving them in private files categorized according to each country, I started to look for specific consonants, especially those that are usually problematic, and to examine whether there is more than one way to write them. For example, the qaf in some

\footnotetext{
${ }^{12}$ Many of the particular cases are restricted to certain areas-for example <2> is used for glottal stop only in Egypt and the Levant.

${ }^{13}$ I also gathered data from different parts in the Arab World.
} 
places can be written as $\langle 8\rangle,\langle\mathrm{g}\rangle$, or $\langle\mathrm{q}\rangle$. I then checked whether the same written variations appeared in both males' and females' writings.

In the following sections, I present and analyze the collected data. The sections are divided according to the investigated phoneme rather than the country in which these phonemes appear, in order to avoid repetition and to make it easier for the reader to understand, compare, and go back and forth among the presented data, information, and discussions.

\subsection{General Observations}

Before presenting the data and the findings, it is crucial to explain several points. People who use EA usually write their spoken dialect, but in some cases they are not entirely sure how to write a word or letter because the conventions are not fully developed. It is significant, however, that this type of confusion is clearly decreasing over time as spelling is becoming more fixed. Sometimes they do not write as they speak because a standardized written form of the local dialect has developed - e.g., in Israel/Palestine the form $\langle 2\rangle$ for qaf, generally understood to correspond to pronouncing this phoneme as a glottal stop, has begun to spread to rural EA users who do not pronounce the qaf as a glottal stop. Usually it is people who are younger than 28 years old who are thus influenced because they are concerned with prestige.

Another point is that EA writers try to avoid controversial forms, as in Jordan, where $\langle 8\rangle$ is used by rural speakers and Bedouins as a compromise in order to avoid the two extreme forms $\langle\mathrm{g}\rangle$ and $\langle 2\rangle$, which are strongly associated with particular groups. Examples of these phenomena will be presented later.

One clear pattern is that people who are over 28 years old tend to use digraphs such as $\langle\mathrm{kh}\rangle$ and $\langle\mathrm{gh}>$ for khaa' and ghain much more than monograph numerals, i.e., among older people digraphs are more prevalent while among younger people numerals are. However, in particular cases, there is a disadvantage to using digraphs in that the two letters can be interpreted as being two monographs. Take for instance the word [btxarrib] ("you are ruining it"). If written as <btkhrib>, it might be read as [btkahrib] ("It causes an electric shock"), with the $\langle\mathrm{k}\rangle$ and $<\mathrm{h}>$ being interpreted as representing separate phonemes. There is also a more general advantage to using monographs: It requires only one keystroke. As a result, there is a general trend towards using monographs

In the following sections, I will analyze the written forms of different consonants, the definite article, and negation in the EA writings of Facebook users in the Levant. Sometimes I excluded certain areas in certain sections either because there are not enough data or because the results are in no way significant.

\subsection{Qaf (/q/)}

The letter qaf is one of the most common and variable letters in spoken Arabic. Qaf is pronounced as [q] in some villages in Israel/Palestine, and in some places in Jordan, Syria, and Lebanon. It is pronounced as $[\mathrm{g}]$ by all Bedouins, some villagers in the Lower Galilee (in the Ben Amir Meadow) in Israel, Jordan, and Syria. Qaf is pronounced as [s] by urban people and Christians in Israel/Palestine, Lebanon, Syria, and Jordan. Qaf is pronounced as [k] in the Triangle region in Israel and the villages in the Palestinian territories. 
Usually, people write their local pronunciation of qaf when they are writing to someone from the same region that uses the same pronunciation, or they will write a regional standard form, which varies from region to region, even if it does not correspond to their spoken language.

\subsection{Qaf in Jordan}

Although it is of particular interest, very few dialectal studies of the Arabic spoken in Jordan have been conducted. The population in Jordan is divided into three main groups:

1. Palestinian refugees and children of Palestinian refugees;

2. Bedouins (non-urban);

3. Urban non-Palestinians.

In my discussion here, urban non-Palestinians will be termed "Jordanians."

Jordan comprises three main geo-dialectal areas: (1) the area close to the Iraqi and Syrian borders (Horan); (2) the area close to the Hijaz and the Saudi Arabian borders; and (3) the center of Jordan and the areas along the Israeli-Palestinian border. The fact that Jordan is surrounded by three different dialectal groups leads to the phenomenon of a language or dialect continuum. The dialect of the inhabitants of the area close to the Iraqi borders belongs to the Iraqi group of dialects, those close to the Saudi Arabian border speak the Bedouin dialect, which belongs to the Peninsular Arabic group of dialects, and those in the central part of the country and near the Israeli-Palestinian border speak the Levantine dialect, which belongs to the Syrian-Palestinian group of dialects.

I will focus on the two main cities in Jordan, Irbid and the capital city Amman. It is important to mention that the population in these cities includes immigrants from Syria and Palestine. The first Palestinian immigration wave occurred in 1948, consisting of the Palestinian urban elite from Haifa, Nablus, and Jerusalem. The second wave occurred in 1967, consisting of mainly rural Palestinians. These immigrants became citizens of Jordan and assumed power in politics and the military, and hence they had to associate themselves with a Jordanian - as opposed to a Palestinian identity. Urban Palestinian-Jordanians who are in politically dominant positions therefore use the Jordanian dialect in public (Al-Wer, 2007).

The contribution of women in Jordan to the labor force is very modest. They are involved in very restricted areas, such as education, the financial sector, and social services. These types of jobs demand a pan-Levantine urban linguistic norm (Al-Wer, 2007).

\subsubsection{Qaf Written by Irbidawis}

In the following sections, I will discuss the letter qaf as written in EA by Jordanian teenagers from Irbid. Irbid is an interesting city in that its inhabitants pronounce qaf in a number of different ways. Thus, in Irbid women generally say [?], while men usually say [q] and sometimes [g] (especially rural Palestinians). In EA, qaf can be written as $\langle q\rangle,\langle 2\rangle$ or $\langle 8\rangle$. I will focus on the Jordanians in this section.

An essential piece of information pertaining to the analysis of the data is that the phonetic value of $\langle 8\rangle$ is actually vague. When EA first came into existence, the $\langle 8\rangle$ was used to denote the letter qaf in the Gulf because with its two loops it looks like the Latin letter $\langle\mathrm{g}\rangle$ in Windows 
Times New Roman font. This standard was adopted in Jordan, but there it can be understood to represent not only [g] but also [q]; however, it does not correspond to [?]. ${ }^{14}$ Some inhabitants of Irbid say [q] and write it as $\langle\mathrm{q}\rangle$ or $\langle 8\rangle$, while others say $[\mathrm{g}]$ and write this also as $\langle 8\rangle$ or $\langle\mathrm{g}\rangle$. The form $\langle 8\rangle$, then, can represent either $\langle\mathrm{g}\rangle$ or $\langle\mathrm{q}\rangle$. This is a clever solution to a complicated sociolinguistic problem, in that teenagers can use $\langle 8\rangle$ when they are not comfortable using either $\langle\mathrm{g}\rangle$ or $\langle 2\rangle$, because the former is too much associated with Bedouins and rough masculinity while the latter is too much associated with Palestinians and femininity. Their interlocutors are not able to discern whether the $<8>$ denotes [g] or [q]. Particularly, because Facebook is a public forum which people from a variety of different groups can see, writers prefer to avoid forms which are too strongly stereotyped. For example, males living in rural areas would be concerned that male friends from their village not see that they are writing $<2>$, because this is regarded as a feminine form. On the other hand, if their friend list includes the other gender or strangers, they prefer to write with $\langle q\rangle$ rather than $\langle\mathrm{g}\rangle$, because they do not feel comfortable using $\langle 2\rangle$ for various reasons, such as societal and peer group pressure. Therefore, since using $\langle 8\rangle$ can be understood as either [g] or [q], it is the most convenient written form for this group of people.

\subsubsection{Qaf in Irbid-Jordanian Females' Facebook Writing}

I will now present a study of the use of the letter qaf on Facebook among Irbidawi females and males.

Table 1: qaf written on Facebook among Irbidawi females and males

\begin{tabular}{|l|l|l|l|l|}
\hline & $\langle 2\rangle$ & $\langle\mathrm{q}\rangle$ & $\langle 8\rangle$ & $\mathrm{N}$ \\
\hline Maha $^{15}$ & $81 \%$ & $9 \%$ & $9 \%$ & 64 \\
\hline Salma & $24 \%$ & $0 \%$ & $76 \%$ & 21 \\
\hline Lamees & $91 \%$ & $9 \%$ & $0 \%$ & 85 \\
\hline Qasim & $44 \%$ & $3 \%$ & $53 \%$ & 68 \\
\hline Firas & $18 \%$ & $0 \%$ & $82 \%$ & 50 \\
\hline Abed & $60 \%$ & $34 \%$ & $65 \%$ & 65 \\
\hline
\end{tabular}

The data above show that $\langle 2\rangle$ is much more common among females, and two of the three females use it the overwhelming majority of the time. However, Salma uses much more $\langle 8\rangle$ than the other two females. The most obvious explanation is that she's Jordanian without a foreign mother, and her Facebook friends are close friends and family.

Moreover, there is a general pattern of males using $\langle 2\rangle$ a lot when writing to females, but not when writing to other males.

Table 2: Jordanian males writing to other males

\begin{tabular}{|l|l|l|l|l|}
\hline & $\langle 2\rangle$ & $\langle\mathrm{q}\rangle$ & $\langle 8\rangle$ & $\mathrm{N}$ \\
\hline Qasim & $0 \%$ & $0 \%$ & $100 \%$ & 31 \\
\hline Firas & $18 \%$ & $0 \%$ & $82 \%$ & 50 \\
\hline Abed & $13 \%$ & $69 \%$ & $19 \%$ & 16 \\
\hline
\end{tabular}

\footnotetext{
${ }^{14}$ Two Jordanian teenagers from Irbid told me this via Skype and MSN.

${ }^{15}$ All the names used in the paper are pseudonyms.
} 
Table 3:Jordanian males writing to other females

\begin{tabular}{|l|l|l|l|l|}
\hline & $\langle 2\rangle$ & $\langle\mathrm{q}\rangle$ & $\langle 8\rangle$ & $\mathrm{N}$ \\
\hline Qasim & $86 \%$ & $0 \%$ & $14 \%$ & 35 \\
\hline Firas & - & - & - & - \\
\hline Abed & $76 \%$ & $22 \%$ & $2 \%$ & 49 \\
\hline
\end{tabular}

When writing to males, Qasim and Firas use $<8>$ most of the time; however, Abed uses $\langle\mathrm{q}\rangle$ much more. This is because Abed is a university student and he has many Facebook female friends. Since $\langle q\rangle$ is more prestigious than $\langle 8>$ and still sounds masculine, Abed prefers to use it.

\subsubsection{Qaf in EA - Amman}

Since Amman is the capital city of Jordan, many of its inhabitants are rich, educated, and in a prestigious social position. Although many pronounce qaf as a glottal stop ['], sometimes men deviate from this pattern and say [q] or [g]. In EA, males and females alike tend to write [q] as $\langle 2\rangle$. I observed the writings of two Jordanian males and two females in Amman. They all used $\langle 2\rangle$; however, I found a few examples in one of the two males' writings where $\langle 8\rangle$ is used, which corresponds to [q] in words that are usually masculine, Fus $a$, or not normally pronounced with a $[\mathrm{g}] .^{16}$

I hypothesized that, in general, males and females write $\langle 2>$ for $q a f$. To prove my hypothesis I collected the following data:

Table 4: $q a f^{17}$ - by Jordanian Muslim males and females from Amman

\begin{tabular}{|l|l|l|l|}
\hline & $\langle 2\rangle$ & Other & $<2>\%$ \\
\hline $\begin{array}{l}\text { Ahmad (14-year-old } \\
\text { male) }\end{array}$ & 73 & 3 & $96 \%$ \\
\hline $\begin{array}{l}\text { Adam (18-year-old } \\
\text { male) }\end{array}$ & 59 & 3 & $95 \%$ \\
\hline $\begin{array}{l}\text { Iman (17-year-old } \\
\text { female) }\end{array}$ & 93 & 0 & $100 \%$ \\
\hline $\begin{array}{l}\text { Shireen (18-year-old } \\
\text { female) }\end{array}$ & 88 & 2 & $98 \%$ \\
\hline
\end{tabular}

\footnotetext{
${ }^{16}$ In many studies, of which that of Abdel-Jawad (1981) is one, it was found that men tend to use more Fusha lexical items, which contain the lexical phoneme /q/, than women do.

${ }^{17}$ There are a very small number of tokens in which qaf is not written at all, presumably because this corresponds to a pronunciation as a glottal stop.

${ }^{18}$ Ahmad and Adam say [?].
} 
The results show clearly that $<2>$ for qaf is not a gender indicator but a standardized form in Amman. It is important to mention that males who live in Amman and who are of urban background may pronounce the qaf as [']. However, in many working-class areas, males tend to use the native variant $[\mathrm{g}]$.

To summarize, $<2>$ is by far the most common form in Amman and Irbid. However, Irbidawi males use $<8>$ with each other, and also Salma uses $<8>$ since she has only her friends and relatives as Facebook friends.

\subsection{Lebanon}

The qaf in Lebanon has different pronunciations, ${ }^{19}$ the most frequent and dominant being [']. The following table presents the findings:

Table 5: qaf in Lebanon

\begin{tabular}{|l|l|l|l|}
\hline & $\langle 2\rangle$ & zero $^{20}$ & $\langle\mathrm{k}\rangle /\langle\mathrm{q}\rangle$ \\
\hline Tokens & 74 & 12 & 2 \\
\hline Percentages & $84 \%$ & $14 \%$ & $2 \%$ \\
\hline
\end{tabular}

The results show that the most frequent form used is $\langle 2\rangle$, followed by zero. The other forms, $\langle\mathrm{q}\rangle$ and $\langle\mathrm{k}\rangle$, are used with words taken from classical Arabic.

\subsection{Israel/Palestine}

In this study, I observed the letter $q a f^{21}$ on Facebook (wall postings and comments only) and MSN Messenger in the writings of teenagers from Nazareth in northern Israel, an Arab city in Israel whose citizens are Muslims and Christians. I also observed the letter qaf on Facebook and MSN in the writings of teenagers from Iksal, an Arab village in Israel about 6 kilometers from Nazareth, whose citizens are only Muslims, in order to show to what extent the written dialect of Nazareth affects the written dialect of Iksal. I will try to prove the following hypothesis:

Many teenagers write in CMC using a developing regional standard based on the city dialect rather than their local dialect.

It is important to bear in mind that $\langle 2\rangle,\langle\mathrm{q}\rangle \mid\langle\mathrm{k}\rangle$, and $\langle\mathrm{g}\rangle$ are understood to correspond to the glottal stop [?], [q], and [g] respectively. There is a general tendency for rural speakers to adopt urban pronunciations when speaking because of overt prestige, and the same general tendency is found in EA writing, but it is much stronger in the sense that many rural speakers, particularly below the age of 23 or so, will write $\langle 2\rangle$ even if they do not say the glottal stop. That is, the spread of $\langle 2\rangle$ is the same general phenomenon as the spread of the glottal stop, but it has gone much farther and faster in writing than in speech. In order to prove this hypothesis, I studied the letter qaf in the spoken and written dialects of subjects aged 16-23. This study is

\footnotetext{
${ }^{19}$ See Behnstedt (1997: map 9) about the phoneme /q/ in Syria and Lebanon.

${ }^{20}$ One example of the qaf pronounced as a glottal stop followed by $d^{\varsigma} a m m a h$ was written as <ou> in the word <oulli> (tell me); the qaf here is written with a zero.

${ }^{21}$ I could find very few examples for $q a f$ pronounced as a glottal stop written with a zero, such as $\langle 0\rangle$, $\langle\mathrm{e}\rangle$ and $<\mathrm{a}>$; therefore, I focused on the more dominant forms.
} 
divided into two parts, Nazareth, and Iksal. Each section will represent specific features in the two dialects in an attempt to test the above hypothesis.

\subsubsection{Nazareth}

The Nazarene dialect has two variant pronunciations of the letter qaf. The pronunciation of [q] is associated with Muslims and males, while the [?] is associated with Christians and females. In the following subsections I present data collected from Nazarene males and females, Muslims and Christians, who are interacting with other Nazarenes or Iksalis on Facebook. Usually Nazarene Muslim males tend to use $\langle\mathrm{q}\rangle$ and $\langle\mathrm{k}\rangle$ in interaction with males to show their masculinity, only rarely using $\langle 2\rangle$ when joking. Some also use $\langle\mathrm{q}\rangle \mid\langle\mathrm{k}\rangle$ with females, but some tend to use $\langle 2\rangle$ in order to appear less rough. It is still not clear what the general trend is, but it is clear that there are two groups: those who want to appear gentle and those who want to show their masculinity.

The following table shows the results of the collected data:

Table 6: Nazarene qaf

\begin{tabular}{|l|l|l|}
\hline Facebook writings & N & $<2>\%$ \\
\hline Muslim males to males & 44 & $14 \%$ \\
\hline Muslim males to females & 54 & $41 \%$ \\
\hline Muslim females to males & 98 & $71 \%$ \\
\hline Muslims females to females & 67 & $73 \%$ \\
\hline Christian males to males & 70 & $75 \%$ \\
\hline Christian males to females & 43 & $88 \%$ \\
\hline Christian females to males & 45 & $88 \%$ \\
\hline Christian females to females & 41 & $86 \%$ \\
\hline
\end{tabular}

It is clear that Muslim males do not use $<2>$ frequently when corresponding with other males; however, they use it more with females. The data show that $\langle 2\rangle$ is the general form for everyone in Nazareth except Muslim males, and even they use it almost half the time when corresponding with females.

Although $\langle 2\rangle$ is generally used by all Christians and Muslim females in Nazareth, $\langle\mathrm{k}\rangle$ or $\langle\mathrm{q}\rangle$ are still occasionally used with words in Fusha and words that can only be pronounced with qaf.

\subsubsection{Iksal}

I conducted two different research studies on Iksal. The first study found that youngsters in Iksal speak one dialect and write in another on CMC. The aim of the second study was to find under what circumstances teenagers in Iksal change their original dialect. This was done by studying the letter qaf. In general, Iksalis pronounce the letter qaf as [g].

\subsubsection{Spoken and Written qaf in Iksal}


I investigated the letter qaf in the writing of two subjects, both 18 year-old girls from Iksal, a village in the Galilee, corresponding with other females, from the same village or from outside the village, on Facebook and MSN Messenger.I also recorded the same two girls in casual speech with me, to examine whether or not these girls consistently use [g] in their everyday speech. It is worth mentioning that I know these two subjects personally, a fact which helped me to ensure that the results reflected their real usage.

Lina was recorded for 55 minutes and 77 tokens of the letter qaf were collected from her speech, while Miriam was recorded for 25 minutes and 63 tokens of qaf were collected. The results are shown in Table 7:

Table 7: Spoken data for the letter qaf collected from two Iksali females

\begin{tabular}{|l|c|c|cc|}
\hline & {$[\mathrm{g}]$} & other pronunciations & $\mathrm{g} \%$ & \\
\hline Lina & 77 & 0 & $100 \%$ \\
\hline Miriam & 63 & 0 & & $100 \%$ \\
\hline
\end{tabular}

I also collected data from these two girls' Facebook wall postings. ${ }^{22}$

Table 8 presents the results:

Table 8: Written data collected from the wall postings of the same two Iksali females

\begin{tabular}{|l|l|l|l|}
\hline & $\langle 2\rangle$ & $\langle\mathrm{g}\rangle$ & $\langle\mathrm{g}\rangle \%$ \\
\hline Lina & 43 & 0 & $0 \%$ \\
\hline Mariam & 28 & 0 & $0 \%$ \\
\hline
\end{tabular}

The results presented in Tables 7 and 8 show that some teenagers in Iksal speak one dialect and write another, i.e., they say $\langle\mathrm{g}\rangle$, but write $\langle 2\rangle$. Social pressure is the main reason why they change their dialect. While in conversation with another Iksali, a person from Iksal speaks the local dialect freely, the same person usually speaks in a more urban dialect when talking to a stranger, especially if this is the dialect that the stranger speaks. This pattern is even more prominent in writing than in speech. Hence, people who have urban contacts or who have friends who have urban contacts tend to write a more urban and prestigious dialect. This was even more evident when I investigated the writing of the same two girls, but this time on MSN.

Table 9: MSN data collected from the same two Iksali females

\begin{tabular}{|l|l|l|l|}
\hline & $\langle 2\rangle$ & $\langle\mathrm{g}\rangle$ & $\langle\mathrm{g}\rangle \%$ \\
\hline Lina & 68 & 20 & $23 \%$ \\
\hline Miriam & 33 & 14 & $30 \%$ \\
\hline
\end{tabular}

\footnotetext{
${ }^{22}$ The representation tends to change, depending on whether the interlocutor is in-group (friend) orout-group (stranger). This is true for both Facebook and MSN Messenger. Yet, it is more true on Facebook since it is less private than MSN.
} 
The girls used $<\mathrm{g}>$ with relatives and close friends, while with others - with urban people, and even with people from the same village with whom they were less well acquainted - they used $<2\rangle$. The reason for this is that females are usually concerned about their prestige. The bottom line is that EA writers are absorbing the idea that $\langle 2\rangle$ is the standard way to write qaf; and other ways of writing it are restricted to particular environments.

\subsection{Pharyngeals and Uvular Fricatives (haa' (/h/)/ 'ayin (/S/)/ khaa'(/x/)/ ghain $(/ \mathbf{s} /))$}

This section is divided into two parts: proper nouns and other usages. By "other usages" I mean anything other than proper nouns, such as wall postings and chatting. I decided to divide the section into two functions since in most of these countries, youngsters make this distinction of using $<\mathrm{h}>$ for $[\mathrm{\hbar}],<\mathrm{kh}>$ for $[\mathrm{x}],<\mathrm{gh}>$ for $[\mathrm{b}]$ and $<\mathrm{a}>$ for $[\mathrm{G}]$ with proper nouns and numerals in all other usages.

\subsection{Proper Nouns}

Since the data are more or less homogenous for all the countries, I decided to use one table for each phoneme to present the data. See Table 10:

Table 10: $\hbar a a^{\prime}$ in proper nouns

\begin{tabular}{|l|l|l|}
\hline & $\langle\mathrm{h}\rangle$ & $\langle 7\rangle$ \\
\hline Jordan & 13 & 0 \\
\hline Lebanon & 17 & 1 \\
\hline Israel/Palestine & 67 & 1 \\
\hline
\end{tabular}

In all the countries presented in Table 10, EA users almost always use $<\mathrm{h}>$ to write $\hbar a a$ 'in proper nouns. The following table gives data for 'ayin, which is never written in proper nouns:

Table 11: 'ayin in proper nouns

\begin{tabular}{|l|l|}
\hline & Zero $(\langle\mathrm{a}\rangle|\langle\mathrm{o}\rangle|\langle\mathrm{e}\rangle|\langle\mathrm{i}\rangle|\langle\mathrm{u}\rangle)$ \\
\hline Jordan & 12 \\
\hline Lebanon & 28 \\
\hline Israel/Palestine & 13 \\
\hline
\end{tabular}

Data for khaa' are given in Table 12:

Table 12:khaa' in proper nouns

\begin{tabular}{|l|l|l|l|}
\hline & $\langle\mathrm{kh}\rangle$ & $\langle 5\rangle$ & $\left\langle 7^{\prime}\right\rangle$ \\
\hline Jordan & 22 & 0 & 0 \\
\hline Lebanon & 16 & 0 & 0 \\
\hline Israel/Palestine & 36 & 1 & 0 \\
\hline
\end{tabular}

And data on ghain are given in Table 13: 
Table 13: ghain in proper nouns

\begin{tabular}{|l|l|l|l|l|l|l|}
\hline & $\langle\mathrm{gh}\rangle$ & $\left\langle\mathrm{g}^{\prime}\right\rangle$ & $\langle 8\rangle$ & $\left\langle 3^{\prime}\right\rangle$ & $\left\langle{ }^{\prime} 3\right\rangle$ & $\langle 4\rangle$ \\
\hline Jordan & 18 & 0 & 0 & 0 & 0 & 0 \\
\hline Lebanon & 13 & 0 & 0 & 0 & 0 & 0 \\
\hline Israel/Palestine & 28 & 0 & 0 & 2 & 0 & 0 \\
\hline
\end{tabular}

The reason for using $\langle\mathrm{h}\rangle,\langle\mathrm{gh}\rangle,\langle\mathrm{kh}\rangle$, and zero in proper nouns might be that this system was originally established a long time ago, so that people could write their names in Latin.

Moreover, using numerals is not practical for some functions, such as when people want to put names in alphabetical order.

\subsection{Other Usages}

In this section, I investigate how these four letters are written in usages other than proper nouns. The form used for $\hbar a a^{\prime}$ in other usages in Jordan and Israel/Palestine is $\langle 7\rangle$. In Lebanon the dominant form used is also $\langle 7\rangle$, although $\langle\mathrm{h}\rangle$ is still sometimes used. In general, the main form used for 'ayin is $\langle 3\rangle$, but zero is occasionally used.

The situation regarding khaa' and ghain is more complex. For khaa' $<5>$ is the most common form, while ghain is most frequently written as $\langle 3$ ' $>$ in Jordan, Israel/Palestine, and $\langle\mathrm{gh}\rangle$ in Lebanon. The situation is, however, even more complicated, as we will see in this section.

\subsubsection{Haa'}

In all the countries that I investigated, $\hbar a a^{\prime}$ is written as $\langle 7\rangle$ in usages other than proper names.

Table 14: $\hbar a a^{\prime}$ written in the Levant

\begin{tabular}{|l|l|l|l|}
\hline & $\langle 7\rangle$ & $\langle\mathrm{h}\rangle$ & $<7>\%$ \\
\hline Jordan & 99 & 0 & $100 \%$ \\
\hline Lebanon & 64 & 7 & $90 \%$ \\
\hline Israel/ Palestine & 79 & 0 & $100 \%$ \\
\hline
\end{tabular}

\subsection{2. 'Ayin}

In cases other than proper names, 'ayin is almost always everywhere written as $<3>$.

Table 15: 'ayin written in the Levant

\begin{tabular}{|l|l|l|l|}
\hline & $\langle 3\rangle$ & Zero & $<3>\%$ \\
\hline Jordan & 49 & 3 & $94 \%$ \\
\hline Lebanon & 75 & 1 & $98.7 \%$ \\
\hline Israel/Palestine & 117 & 7 & $94.4 \%$ \\
\hline
\end{tabular}




\subsubsection{Khaa'}

$K h a a^{\prime}$ can be represented by the numerals $\langle 5\rangle$ or $\langle 7$ ' $\rangle$ or the digraph $\langle\mathrm{kh}\rangle$, the form $\langle 5\rangle$ being the most common everywhere. The situation for khaa' is similar to the situation for $\hbar a a$ ', but there is more variation for khaa'.

The following table presents a statistical summary of the situation for khaa':

Table 16: A statistical summary for khaa'

\begin{tabular}{|l|l|l|l|l|}
\hline & $\langle\mathrm{kh}\rangle$ & $\langle 7\rangle$ & $\langle 5\rangle$ & Tokens \\
\hline Jordan & $0 \%$ & $0 \%$ & $100 \%$ & 86 \\
\hline Lebanon & $38 \%$ & $1.5 \%$ & $60.5 \%$ & 203 \\
\hline $\begin{array}{l}\text { Israel/ } \\
\text { Palestine }\end{array}$ & $0.5 \%$ & $9.6 \%$ & $89.9 \%$ & 198 \\
\hline
\end{tabular}

Since in Lebanon age affects the writing, I divided the Lebanese EA writers into four age groups, 18-21 years, 22-24 years, 25-27 years, and 28-30 years. Table 32 shows the results:

Table 17: khaa' in Lebanon

\begin{tabular}{|l|c|l|l|l|l|l|}
\hline Age & $\langle\mathrm{kh}\rangle$ & \multicolumn{3}{l|}{$\langle 5\rangle$} & $\left\langle 7^{\prime}\right\rangle$ & \\
\hline $18-21$ & 6 & $10.9 \%$ & 46 & $83.6 \%$ & 3 & $5.5 \%$ \\
\hline $22-24$ & 14 & $28 \%$ & 36 & $72 \%$ & 0 & $0 \%$ \\
\hline $25-27$ & 19 & $33.33 \%$ & 38 & $66.66 \%$ & 0 & $0 \%$ \\
\hline $28-30$ & 38 & $92.7 \%$ & 3 & $7.3 \%$ & 0 & $0 \%$ \\
\hline
\end{tabular}

Writers who are 18-21, 22-24, and 25-27 years of age tend to use $\langle 5\rangle$ more than $\langle\mathrm{kh}\rangle$. However, those who are 25-27 years old, tend to use $<\mathrm{kh}>$ more than those who are 18-21 and 22-24 years old. Writers who are older than $28 \mathrm{use}<\mathrm{kh}>$ much more than those who are younger. Thus there is a clear tendency for $\langle 5\rangle$ to replace $\langle\mathrm{kh}\rangle$. $\langle 7$ ' $\rangle$ is barely used at all.

\subsubsection{Ghain}

The most common form used for ghain is <'3>. However, there are some other forms which are more common in some places than in others, such as $\langle\mathrm{gh}\rangle$ and $\langle 8\rangle$ in Lebanon. Table 46 presents a statistical summary of the situation for ghain. As can be seen, the most common forms are $\langle$ ' 3$\rangle$ in Kuwait and UAE, $\langle 3$ ' $\rangle$ in Jordan, Israel/Palestine, and $\langle\mathrm{gh}\rangle \mid\langle 8\rangle$ in Lebanon:

Table 18: A statistical summary of the situation for ghain

\begin{tabular}{|l|l|l|l|l|l|l|l|l|l|l|}
\hline & $\left\langle 33^{\prime}\right\rangle$ & $\langle 3\rangle$. & $\left\langle{ }^{\prime} 3\right\rangle$ & $\langle 8\rangle$ & $\langle 4\rangle$ & $\langle\mathrm{gh}\rangle$ & $\langle\mathrm{r}\rangle$ & $\langle\mathrm{g}\rangle$ & $\langle\mathrm{g}\rangle$ & Tokens \\
\hline Jordan & $\begin{array}{l}64.5 \\
\%\end{array}$ & $0 \%$ & $\begin{array}{l}34.2 \\
\%\end{array}$ & $0 \%$ & $\begin{array}{l}1.3 \\
\%\end{array}$ & $0 \%$ & $0 \%$ & $0 \%$ & $0 \%$ & 79 \\
\hline Lebanon & $0 \%$ & $0 \%$ & $0 \%$ & $17.4 \%$ & $0 \%$ & $\begin{array}{l}72.1 \\
\%\end{array}$ & $0 \%$ & $\begin{array}{l}10.5 \\
\%\end{array}$ & $0 \%$ & 86 \\
\hline
\end{tabular}




\begin{tabular}{|l|l|l|l|l|l|l|l|l|l|l|}
\hline $\begin{array}{l}\text { Israel/ } \\
\text { Palestine }\end{array}$ & $\begin{array}{l}81.2 \\
\%\end{array}$ & $\begin{array}{l}0.4 \\
\%\end{array}$ & $0 \%$ & $12.7 \%$ & $\begin{array}{l}1.2 \\
\%\end{array}$ & $0 \%$ & $0 \%$ & $1.9 \%$ & $\begin{array}{l}2.7 \\
\%\end{array}$ & 260 \\
\hline
\end{tabular}

Regarding the form $<8>$ in Lebanon and Israel/Palestine, I distinguished the users according to age. It is clear that the form $\langle 8\rangle$ is more common among younger users (under 21 years old). The following table illustrates the results:

Table 19: ghain in Lebanon

\begin{tabular}{|r|r|r|r|r|r|r|r|r|r|r|}
\hline Age & \multicolumn{2}{|r|}{$<\mathrm{gh}>$} & \multicolumn{2}{r|}{$<\mathrm{g}>$} & \multicolumn{2}{|r|}{$<8>$} & \multicolumn{2}{|r|}{$<3$} & \multicolumn{2}{|r|}{$<3>$} \\
\hline $18-21$ & 9 & $37.5 \%$ & 3 & $12.5 \%$ & 12 & $50 \%$ & $0 \%$ & 0 & $0 \%$ & 0 \\
\hline $22-24$ & 11 & $61.1 \%$ & 4 & $22.2 \%$ & 3 & $16.7 \%$ & $0 \%$ & 0 & $0 \%$ & 0 \\
\hline $25-27$ & 19 & $95 \%$ & 1 & $5 \%$ & 0 & $0 \%$ & 0 & $0 \%$ & $0 \%$ & 0 \\
\hline $28-30$ & 23 & $96 \%$ & 1 & $4 \%$ & 0 & $0 \%$ & $0 \%$ & 0 & 0 & $0 \%$ \\
\hline
\end{tabular}

Table 20: The influence of age on writing <8>

\begin{tabular}{|l|l|l|l|}
\hline & Younger than 18 & $18-21$ years old & Above 22 \\
\hline$\langle 8\rangle$ & 28 & 4 & 1 \\
\hline Percentage & $85 \%$ & $12 \%$ & $3 \%$ \\
\hline
\end{tabular}

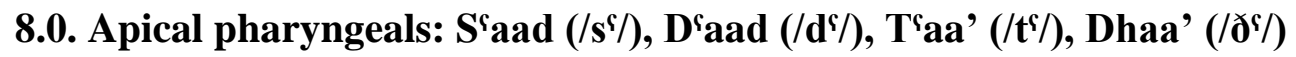

The pharyngealization of these sounds is variable in many dialects. Non-pharyngealized forms are generally more common among females, urban people, and non-Bedouins; and to a certain extent, even when they do pronounce these sounds pharyngealized, the pharyngealization is weaker. This difference is reflected in EA: There is a clear tendency for people who pharyngealize these sounds less to write them in the same way as they do non-pharyngealized sounds, while those who pharyngealize these sounds more strongly write them differently, using numbers. The situation is particularly complicated in Jordan, where the dialect is a very mixed Bedouin/Levantine one, resulting in males tending to use the Bedouin pronunciation and write distinctive pharyngealized sounds, while females, preferring the Levantine pronunciation, do not write these sounds. In this section I will discuss $s^{\varsigma} a a d, d^{\varsigma} a a d, t^{\varsigma} a a^{\prime}$, and Dhaa' in different countries, leaving the discussion of these variables in Jordan until the end.

\subsection{S`aad}

The letter $s^{\uparrow} a a d$ is pronounced as a pharyngeal in Jordan (rural and males), Lebanon (rural) and Israel/Palestine (rural and males). However, pharyngealization in writing is manifest only in 
Jordan by using <9>. In Lebanon and Israel/Palestine, pharyngealization is only occasionally emphasized by writing capital $\langle$ S $\rangle$.

\subsubsection{S`aad in Lebanon and Israel/Palestine}

The letter $s^{\varsigma} a a d$ is usually not pharyngealized in speech (urban), and is usually written the way it is pronounced. However, very rarely capital $\langle\mathrm{S}\rangle$ is used to indicate pharyngealization.

The letter $s^{\varsigma}$ aad is pronounced [s], and written as $\langle\mathrm{s}\rangle$. See table 21:

Table 21: $s^{\varsigma} a a d$

\begin{tabular}{|l|l|l|l|}
\hline & $\langle\mathrm{S}\rangle$ & $\langle\mathrm{S}\rangle$ & $\mathrm{N}$ \\
\hline Lebanon & $97 \%$ & $3 \%$ & 39 \\
\hline Israel/Palestine & $98 \%$ & $2 \%$ & 42 \\
\hline
\end{tabular}

\subsection{T'aa'}

The letter $t^{\varsigma} a a^{\prime}$ is sometimes written as a pharyngeal $\langle 6\rangle$ in Jordan and Israel/Palestine; especially by rural and male users, but in Lebanon, it is always written as $\langle t\rangle$. Actually, rural males are more likely to write $\langle 6\rangle$, since this is associated with the fact that they have the most pharyngealized pronunciation.

\subsection{1. $T^{\top}$ aa' in Lebanon and Israel/Palestine}

The letter $t^{\dagger} a a$ is pronounced [t]in Lebanon and urban areas in Israel/Palestine, and it is written $\langle\mathrm{t}\rangle$. When pharyngealization is indicated in Lebanon, it is by capitalization rather than numerals, usually by males, but this is very rare. However, in Israel/Palestine pharyngealization is indicated by using the numeral $\langle 6\rangle$. The numeral $\langle 6\rangle$ is frequently used by males, especially rural males, while the $\langle t\rangle$ is frequently used by females; especially urban females.

See the table below:

Table 22: $t^{\uparrow} a a^{\prime}$

\begin{tabular}{|l|l|l|l|l|}
\hline & $\langle\mathrm{t}\rangle$ & $\langle\mathrm{T}\rangle$ & $\langle 6\rangle$ & $\mathrm{N}$ \\
\hline Lebanon & $97.1 \%$ & $2.9 \%$ & $0 \%$ & 68 \\
\hline $\begin{array}{l}\text { Israel/Palestine: } \\
\text { Rural males }\end{array}$ & $18 \%$ & $0 \%$ & $82 \%$ & 28 \\
\hline $\begin{array}{l}\text { Israel/Palestine: } \\
\text { Rural females }\end{array}$ & $65 \%$ & $0 \%$ & $35 \%$ & 37 \\
\hline $\begin{array}{l}\text { Israel/Palestine: } \\
\text { Urban males }\end{array}$ & $71 \%$ & $0 \%$ & $29 \%$ & 31 \\
\hline $\begin{array}{l}\text { Israel/Palestine: } \\
\text { Urban females }\end{array}$ & $100 \%$ & $0 \%$ & $0 \%$ & 36 \\
\hline
\end{tabular}




\subsection{Dhaa' and $D^{\Upsilon}$ aad}

The letters $D^{\varsigma} a a d$ and $D h a a^{\prime}$ usually overlap in pronunciation. In urban areas in Israel/Palestine, and Lebanon Dhaa' is pronounced as $\left[\mathrm{d}^{\mathrm{S}}\right]$ with light pharyngealization.

\subsubsection{Dhaa' and D’aad in Lebanon and Israel/Palestine}

$D^{\varsigma}$ aad in Lebanon is normally pronounced as [d] and it is written as it is pronounced; $\langle\mathrm{D}\rangle$ is rarely used by males to indicate a pharyngeal pronunciation. Moreover, the letter Dhaa' is also pronounced [d] and normally written as $\langle\mathrm{d}\rangle$. The letter $d^{\varsigma}$ aad in Israeli/Palestinian EA is almost always written as $\langle\mathrm{d}\rangle$. It is rarely written as $\langle\mathrm{D}\rangle$ to emphasize pharyngealization. Dhaa' is also usually written as $\langle\mathrm{d}\rangle$, but it is occasionally written as $\left\langle\mathrm{d}^{\prime}\right\rangle$ or $\left\langle\mathrm{D}^{\prime}\right\rangle$, particularly by rural writers.

Table 23: <d > written with $d^{\varsigma} a a d$

\begin{tabular}{|l|l|l|l|}
\hline & $\langle\mathrm{d}\rangle$ & $\langle\mathrm{D}\rangle$ & $\mathrm{N}$ \\
\hline Lebanon & $87.5 \%$ & $12.5 \%$ & 16 \\
\hline Israel/Palestine & $84.2 \%$ & $15.3 \%$ & 19 \\
\hline
\end{tabular}

Table 24: <d > written with Dhaa'

\begin{tabular}{|l|l|l|l|l|}
\hline & $\langle\mathrm{d}\rangle$ & $\langle\mathrm{D}\rangle$ & $\left\langle\mathrm{d}^{\prime}\right\rangle /\left\langle\mathrm{D}^{\prime}\right\rangle$ & $\mathrm{N}$ \\
\hline Lebanon & $90 \%$ & $10 \%$ & $0 \%$ & 10 \\
\hline Israel/Palestine & $75 \%$ & $0 \%$ & $25 \%$ & 8 \\
\hline
\end{tabular}

\subsection{Apical Pharyngeals in Jordan}

Jordanian EA is influenced to a great extent by Gulf EA. They use $\left\langle 9^{\prime}\right\rangle \mid\left\langle 6^{\prime}\right\rangle,\langle 6\rangle$, and $\langle 9\rangle$ for Dhaa'ld'aad, $t^{\varsigma} a a^{\prime}$, and $s^{\varsigma} a a d$ respectively. However, since the dialect is a mixture of Bedouin and Levantine, these forms are generally more common among males than females. Moreover, the gender distinction in the Jordanian dialect is particularly strong. In the following subsections I will discuss the situation in Irbid and the capital city Amman.

\subsubsection{Irbid}

In this subsection, I discuss the use of the apical pharyngeals in Irbid and how this is influenced by gender.

\subsubsection{S'aad and T'aa' in Irbid}

Irbidawis, both males and females, tend to write either $\langle 6\rangle$ (as in the Gulf) or $\langle t\rangle$ (as in the Levant and Egypt), but males prefer $\langle 6\rangle$ to $\langle t\rangle$. There is no standardization in the use of $\langle t\rangle$ or $\langle 6\rangle$; sometimes capital $\langle\mathrm{T}\rangle$ is used to stress pharyngealization instead of $\langle 6\rangle$ but this is not common. 
Table 25: $t^{\dagger} a a^{\prime}$ in Irbid

\begin{tabular}{|l|l|l|l|l|}
\hline & $\langle\mathrm{t}\rangle$ & $\langle\mathrm{T}\rangle$ & $\langle 6\rangle$ & $\langle 6\rangle \%$ \\
\hline Females & 41 & 0 & 26 & $39 \%$ \\
\hline Males & 9 & 1 & 38 & $79 \%$ \\
\hline
\end{tabular}

The letter $s^{\uparrow}$ aad $/ \mathrm{s}^{\uparrow} /$ also has two EA forms in Jordan, $<\mathrm{s}>$ and $<9>$. Some writers tend to use one more than the other. In general, males tend to use $\langle 9\rangle$ more than females, since $\langle 9\rangle$ might be considered more masculine. In general both forms, $<\mathrm{t}>$ and $\left\langle 6>\right.$ for $/ \mathrm{t}^{\mathrm{s}} /$ and $\langle\mathrm{s}>$ and $\langle 9>$ for $/ \mathbf{s}^{\varsigma} /$, are associated with different genders. In Table 26 are presented the data for 10 males and 10 females from Irbid, who write frequently on their Facebook walls, regarding how many times each group writes $\langle 9\rangle$ and $\left\langle\right.$ s $>$ for $s^{\zeta}$ aad:

Table 26: (Irbid) The usage of $\langle 9\rangle$ and $\langle$ s $>$ among males and females

\begin{tabular}{|l|l|l|lc|}
\hline & $\langle 9\rangle$ & $\langle\mathrm{s}\rangle$ & $\langle 9\rangle \%$ & \\
\hline Females & 64 & 118 & $35 \%$ & \\
\hline Males & 101 & 57 & \multicolumn{2}{|c|}{$64 \%$} \\
\hline
\end{tabular}

The results demonstrate that males use $\langle 9\rangle$ much more frequently than females, while females use $\langle\mathrm{s}>$ more, that is, males tend to use more masculine written forms, while females tend to use the soft feminine $<$ s $>$ more.

\subsubsection{Dhaa' and D'aad}

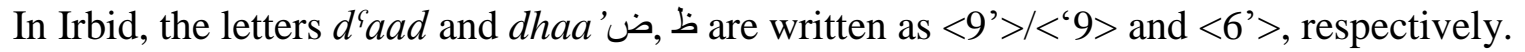
Females tend to prefer the "softer" form of $d^{\top} a a d$, which is $d$, and the softer forms of Dhaa', which are [d] or [z] (depending on the word itself), while males tend to use the dental fricative, which is perceived as being more "masculine." As a result, females usually write d'aad and Dhaa' as $\langle\mathrm{d}\rangle$ and $\langle\mathrm{z}\rangle$ respectively, while males prefer $\langle 9$ ' $\rangle$ and $\langle 6$ ' $\rangle$.

As in other places, the distinction between $d^{\prime} a a d$ and Dhaa' is not always maintained in the spoken Arabic of Jordan, in this case generally because $d^{\prime} a a d$ can often be pronounced as a fricative. For instance, the word [bidrob] can also be pronounced as [bið'rob] ("hits"). Consider the following EA examples taken from Sameer, a 19 year-old Jordanian male from Irbid:

(17) keef rm9'an m3ek?

"How is Ramadan going with you?"

(18) allah 3la al9'alem.

"May God punish the unjust."

In the first example, one cannot tell whether Sameer denoted $d^{\top} a a d$ or $d h a a$ ' by $\langle 9$ ' $\rangle$. This is because Ramadan (رمضان) can be pronounced as [ramad'an] or [ramað'an] depending on one's dialect. However, in the second example the word [al ð'alim] ("the injustice") can be pronounced only with either [ $\left.ð^{\varsigma}\right]$ or $[z]$, so that this is evidence that $<9$ ' $>$ as used by Sameer actually denotes $d h a a^{\prime}$ rather than $d^{s} a a d$. It is worth mentioning that the pharyngealized [d], 
i.e., [ $\mathrm{d}^{\mathrm{c}}$ ], is also written as $<\mathrm{d}>$, and sometimes it is capitalized $(<\mathrm{D}>$ ) in order to stress the pharyngealization. Results for Dhaa' and $d^{\varsigma} a a d$ are presented in Tables27 and 28:

Table 27: Dhaa' in Irbid

\begin{tabular}{|l|l|l|l|l|l|}
\hline & $\left\langle 6^{\prime}\right\rangle$ & $\langle\mathrm{d}\rangle$ & $\langle\mathrm{z}\rangle$ & $\begin{array}{l}\text { Other: }\langle\mathrm{D}\rangle / \\
\langle\mathrm{th}\rangle /\left\langle\mathrm{d}{ }^{\prime}\right\rangle\end{array}$ & $\left\langle 6^{\prime}\right\rangle \%$ \\
\hline Females & 3 & 10 & 6 & 0 & $16 \%$ \\
\hline Males & 18 & 1 & 0 & 0 & $95 \%$ \\
\hline
\end{tabular}

Table 28: $d^{\varsigma} a a d$ in Irbid

\begin{tabular}{|l|l|l|l|l|l|}
\hline & $\left\langle 9^{\prime}\right\rangle /\left\langle{ }^{\prime} 9\right\rangle$ & $\langle\mathrm{d}\rangle$ & $\langle\mathrm{z}\rangle$ & Other: $\langle\mathrm{D}$ & $\left\langle{ }^{\prime} 9\right\rangle /\left\langle 99^{\prime}\right\rangle \%$ \\
\hline Females & 5 & 14 & 0 & 0 & $26 \%$ \\
\hline Males & 22 & 1 & 0 & 2 & $88 \%$ \\
\hline
\end{tabular}

Comparing Tables 25 and 26 with Tables 27 and 28, we see that in Irbid, for all four of these sounds, males use the numerals associated with pharyngeal pronunciation much more frequently than do females.

\subsubsection{Amman}

In this subsection, I investigate whether gender affects the form used to represent apical pharyngeals in Amman.

\subsubsection{S'aad, D'aad, Dhaa' and T'aa'}

I hypothesized that, in general, as in Irbid, males in Amman tend to use $<9>$ to denote $s^{\varsigma} a a d$ and $\left\langle 9\right.$ '> to denote $d^{\varsigma} a a d$, whereas females tend to use $<$ s $>$ for $s^{\varsigma} a a d$ and $<\mathrm{d}>$ for $d^{\varsigma} a a d$. To prove my hypothesis, I collected data from two males and two females from Amman:

1. Khalid, a 14-year-old Jordanian Muslim male.

2. Shadi, an 18-year-old Jordanian Muslim male.

3. Mona, a 17-year-old Jordanian Muslim female.

4. Lana, an 18-year-old Jordanian Muslim female.

Consider the following tables:

Table 30: $s^{\varsigma}$ aad in Amman

\begin{tabular}{|l|l|l|l|}
\hline & $\langle 9\rangle$ & $\langle\mathrm{s}\rangle$ & $\langle 9\rangle \%$ \\
\hline Khalid & 32 & 3 & $91 \%$ \\
\hline Shadi & 43 & 1 & $98 \%$ \\
\hline Mona & 3 & 18 & $14 \%$ \\
\hline Lana & 4 & 11 & $27 \%$ \\
\hline
\end{tabular}


Table 31: $d^{\top} a a d$ in Amman

\begin{tabular}{|l|l|l|l|}
\hline & $\left\langle{ }^{\prime} 9\right\rangle$ & $\langle\mathrm{d}\rangle$ & $\left.<{ }^{\prime} 9\right\rangle \%$ \\
\hline Khalid & 13 & 0 & $100 \%$ \\
\hline Shadi & 21 & 0 & $100 \%$ \\
\hline Mona & 1 & 3 & $25 \%$ \\
\hline Lana & 2 & 5 & $29 \%$ \\
\hline
\end{tabular}

Table 32: Dhaa' in Amman

\begin{tabular}{|l|l|l|l|l|}
\hline & $\left\langle 6^{\prime}\right\rangle$ & $\langle\mathrm{d}\rangle$ & $\langle\mathrm{z}\rangle$ & $\left\langle 6{ }^{\prime}\right\rangle \%$ \\
\hline Khalid & 17 & 4 & 7 & $61 \%$ \\
\hline Shadi & 23 & 5 & 2 & $77 \%$ \\
\hline Mona & 0 & 25 & 13 & $0 \%$ \\
\hline Lana & 2 & 31 & 9 & $5 \%$ \\
\hline
\end{tabular}

Table 33: $t^{\varsigma} a a^{\prime}$ in Amman

\begin{tabular}{|l|l|l|l|}
\hline & $\langle\mathrm{t}\rangle$ & $\langle 6\rangle$ & $<6>\%$ \\
\hline Khalid & 7 & 26 & $79 \%$ \\
\hline Shadi & 4 & 19 & $83 \%$ \\
\hline Mona & 34 & 3 & $8 \%$ \\
\hline Lana & 39 & 5 & $11 \%$ \\
\hline
\end{tabular}

The results clearly show that, as in Irbid, males tend to use pharyngeal letters more than females, while females tend to use $\langle\mathrm{s}\rangle,\langle\mathrm{d}\rangle$, and $\langle\mathrm{t}\rangle$ more than $\langle 9\rangle,\langle 9\rangle$, and $\langle 6\rangle$.

\subsection{Hamza (Glottal Stop) (/?/)}

In the Arabic alphabet, hamza is written as $\langle\boldsymbol{\varepsilon}\rangle$ while in EA it is written as $\langle 2\rangle$; we can obviously notice the great similarity between the two shapes. The general pattern is that $\langle 2\rangle$ is almost always written for hamza in word-medial position and word-final position, but is rarely written in word-initial position. The only exception is that it is often written in initial position in Jordan (51\% of the time) and Israel/Palestine (32\% of the time). Sometimes in EA the hamza is written as zero and only the vowel/diacritic is written as $\langle 0\rangle \mid\langle\mathrm{e}\rangle$ or $\langle\mathrm{i}\rangle /$ and $\langle\mathrm{a}\rangle$. In cases in which qaf is pronounced as a glottal stop, it merges with hamza, and in these cases, qaf is usually written as $\langle 2\rangle$.

\subsection{Jordan}

I counted the instances of hamza $a^{23}$ in the initial, middle, and final positions in the writing of Jordanian teens. The data are presented in Table 34:

\footnotetext{
${ }^{23}$ I checked for gender, specifically because gender is important for many variables in Jordan. However, I could not find any effect.
} 
Table 34: hamza: initial, middle, and final positions in Jordan

\begin{tabular}{|l|l|l|l|}
\hline & Word: initial & Word: medial & Word: final \\
\hline Zero +vowel & 192 & 0 & 0 \\
\hline$<2>+$ vowel & 19 & 0 & 0 \\
\hline$<2>+$ no vowel & 182 & 37 & 5 \\
\hline $\begin{array}{l}\text { None } \\
(\text { no }<2>+ \text { no vowel) }\end{array}$ & 2 & 0 & 0 \\
\hline
\end{tabular}

The results in table 34 indicate that in the initial position, Jordanian teens prefer to omit the hamza and write the vowel that follows, or write the hamza only without the vowel that follows. In the medial and final positions, they prefer to write only the hamza. The frequency of <2> for hamza in initial position is much higher in Jordan than anywhere else.

Table 35: The effect of the following vowel on the representation of hamza (Jordan)

\begin{tabular}{|l|l|l|l|}
\hline & {$[\mathrm{a}]$} & {$[\mathrm{e}]$} & {$[\mathrm{o}]$} \\
\hline$<2>$ & 114 & 54 & 33 \\
\hline Zero & 69 & 89 & 36 \\
\hline$<2>\%$ & $62 \%$ & $38 \%$ & $48 \%$ \\
\hline
\end{tabular}

The results in the table 36 indicate that $\langle 2>$ is more likely to be used when the following vowel is [a] even if it is not written. This suggests that to a certain extent $\langle 2\rangle$ marks also the [a] vowel in the same way that $<3>$ is also particularly associated with [a].

\subsection{Lebanon}

The following table shows the usage of hamza divided into four types: zero +vowel, $\langle 2\rangle+$ vowel, $\langle 2\rangle$ without vowel and no $\langle 2\rangle+$ no vowel. As in Kuwait and the UAE, word-initial $<2>$ is left out the great majority of the time.

Table 36: hamza: initial, middle, and final positions(Lebanon)

\begin{tabular}{|l|l|l|l|}
\hline & Word-initial & Word-medial & Word-final \\
\hline Zero +vowel & 79 & 0 & 0 \\
\hline$<2>+$ vowel & 16 & 0 & 0 \\
\hline$<2>$ without vowel & 0 & 11 & 3 \\
\hline $\begin{array}{l}\text { None } \\
\text { (no<2>+ no vowel) }\end{array}$ & 5 & 0 & 0 \\
\hline
\end{tabular}

\subsection{Israel/Palestine}

As in other Arab countries, Israeli/Palestinian EA users write hamza in four different ways: They write the hamza and the vowel/diacritic that follows the hamza alone, the diacritic without the hamza, and neither the hamza nor the vowel. Thus, I divided the hamza into four groups. Consider the following table: 
Table 37:hamza in Israel/Palestine

\begin{tabular}{|l|l|l|l|}
\hline & Word: initial & Word: medial & Word: final \\
\hline Zero + vowel & 209 & 0 & 0 \\
\hline$<2>+$ vowel & 41 & 2 & 0 \\
\hline$<2>+$ no vowel & 55 & 9 & 13 \\
\hline $\begin{array}{l}\text { None (no }<2>+ \\
\text { no vowel) }\end{array}$ & 15 & 0 & 0 \\
\hline
\end{tabular}

According to the results presented in Table 37, it is evident that EA users prefer not to write the hamza in the initial position but the following diacritic. However, they prefer to use hamza<2> only without the vowel (diacritic) in the medial and final positions.

Table 37 shows the effect of the following vowel; we see that this does not seem to influence the frequency of writing $<2>$ :

Table 37: The effect of the following vowel on the representation of hamza (Israel/Palestine)

\begin{tabular}{|l|l|l|l|}
\hline & {$[\mathrm{a}]$} & {$[\mathrm{e}]$} & {$[\mathrm{o}]$} \\
\hline$\langle 2\rangle$ & 48 & 42 & 6 \\
\hline Zero & 84 & 118 & 7 \\
\hline$\langle 2>\%$ & $36 \%$ & $26 \%$ & $46 \%$ \\
\hline
\end{tabular}

The results in the table above indicate that $\langle 2\rangle$ is more likely to be used when the following vowel is [o] and [a] even if it is not written, but this is only suggestive as there are only 13 tokens of [o] while the difference between [a] and [e] is not statistically significant (chisquare $=3.47$ ).

\subsection{Conclusion}

To sum up the results I am combining the data from this section in Table 38:

Table 38: $\langle 2\rangle+$ vowel and the $\langle 2\rangle$ without vowel together, and the zero+ vowel and the "none" together, for initial position

\begin{tabular}{|l|l|l|l|}
\hline Country & $\langle 2\rangle$ & Zero & $<2>\%$ \\
\hline Jordan & 201 & 194 & $51 \%$ \\
\hline Lebanon & 16 & 84 & $16 \%$ \\
\hline Israel/Palestine & 104 & 224 & $32 \%$ \\
\hline
\end{tabular}

In Jordan, and to a lesser extent Israel/Palestine, that $<2>$ is frequently used for hamza in initial position. 


\subsection{Other letters: Thaa' $(/ \Theta /)$, Dhal $(/ / /)$, Jeem $(/ \mathrm{d} 3 /)$, Sheen $(/ / /)$}

In this section, I discuss variation in writing other letters: thaa' $(/ \Theta /)$, dhal $(/ ð /)$, jeem $\left(/ \mathrm{d}_{3} /\right)$, sheen $(/ \mathrm{J} /)$.

\subsection{Thaa' and dhal}

In this subsection I will discuss the written forms for the letters thaa' and dhal in Levantine EAs.

\subsubsection{Thaa' and dhal in Jordan}

Thaa' in Jordan is pronounced as [Ө] by Bedouins and rural people; however, in Amman and Irbid (especially by females), it is pronounced [t] and occasionally as [s] depending on the word itself. In the following table are the results of my observations of the writings of Irbidawi males and females in order to assess who uses <th> in writing more:

Table 39: thaa' in Jordan

\begin{tabular}{|l|l|l|l|l|}
\hline & $\langle\mathrm{th}\rangle$ & $\langle\mathrm{t}\rangle$ & $\langle\mathrm{s}\rangle$ & $\langle$ th $>\%$ \\
\hline Males & 33 & 10 & 0 & $76.7 \%$ \\
\hline Females & 9 & 37 & 1 & $19.6 \%$ \\
\hline
\end{tabular}

Females tend to write $\langle\mathrm{t}\rangle$ more than males, whereas males prefer $\langle$ th $\rangle$ to $\langle\mathrm{t}\rangle$. These results exactly reflect the way they pronounce thaa', as males tend to use the pronunciation [ $\mathrm{t}]$ less frequently than females (see Al-Ali and Arafa, 2010: 218). It is crucial to understand that this is another example of how, in the Jordanian dialect, gender plays an extremely important role.

The letter dhal in Jordan is written as $\langle\mathrm{d}\rangle,\langle\mathrm{z}\rangle$ or $\langle\mathrm{th}\rangle$, the latter particularly by rural males. I observed the writings of Irbidawis (considered having a rural dialect to a certain extent) and Ammanis (urban dialect). The results are shown in Table 40:

Table 40: dhal for Jordanian males and females

\begin{tabular}{|l|l|l|l|}
\hline & $\langle\mathrm{d}\rangle$ & $\langle\mathrm{z}\rangle$ & $\langle$ th $\rangle$ \\
\hline Rural males & 1 & 0 & 8 \\
\hline Urban males & 7 & 3 & 2 \\
\hline Rural Females & 6 & 2 & 4 \\
\hline Urban females & 9 & 3 & 0 \\
\hline
\end{tabular}

We see here that rural males prefer <th>, like people from Kuwait and UAE, while all other groups mostly use $<\mathrm{d}>$. It is important to mention that some rural females, although pronouncing the dhal as [ð], write $\langle\mathrm{d}\rangle \mid\langle\mathrm{z}\rangle$, as this is understood to be associated with a more prestigious pronunciation. 


\subsubsection{Thaa' and dhal in Lebanon}

The letter thaa' is pronounced in two ways in Lebanon, as [ $\mathrm{t}]$ or $[\mathrm{s}]$, depending on the word. Compare for instance the words $<$ kteer $>$ ("a lot") vs. $<\mathrm{mt} 2 \mathrm{ssir}>24$ ("touched"). However, there are no rules, and usage depends on the intuition of the native speaker of the dialect. ${ }^{25}$ In order to assess the relationship between speech and writing, I asked one of my Lebanese contacts to tell me which words are pronounced with $\langle\mathrm{t}\rangle$ and which with $\langle\mathrm{s}\rangle$ and then coded my results according to this categorization. The results are shown in Tables $40 \mathrm{~A}$ and $40 \mathrm{~B}$ :

Table 40 A: thaa' in Lebanon: words pronounced [ $\mathrm{t}]$

\begin{tabular}{|l|l|l|}
\hline & $\langle\mathrm{t}\rangle$ & $\langle\mathrm{s}\rangle$ \\
\hline Tokens & 76 & 1 \\
\hline Percentages & $100 \%$ & $0 \%$ \\
\hline
\end{tabular}

Table 40 B: thaa' in Lebanon: words pronounced [s]

\begin{tabular}{|l|l|l|}
\hline & $\langle\mathrm{t}\rangle$ & $\langle\mathrm{s}\rangle$ \\
\hline Tokens & 25 & 1 \\
\hline Percentages & $96.2 \%$ & $3.8 \%$ \\
\hline
\end{tabular}

The results show that the writing directly reflects the pronunciation. The number of $\langle t\rangle s$ is greater, but this is only because in general the number of words with $\langle\mathrm{t}\rangle$ is greater; moreover, the words with $\langle\mathrm{t}\rangle$ are used more frequently in Amiyya.

In the Lebanese dialect dhal is pronounced as [d] or [z], depending on the lexical item, or [ð]. In EA it is written $\langle\mathrm{d}\rangle,\langle\mathrm{z}\rangle$, or $\langle$ th $\rangle$. I asked someone from Lebanon on my contact list to help me categorize words according to their pronunciation. The results are shown in Table 41:

Table 41: dhal in Lebanon

\begin{tabular}{|l|l|l|l|}
\hline & $\langle\mathrm{d}\rangle$ & $\langle\mathrm{z}\rangle$ & $\langle$ th $\rangle$ \\
\hline $\begin{array}{l}\text { Classical } \\
\text { Arabic }\end{array}$ & 0 & 1 & 8 \\
\hline Words with [d] & 11 & 0 & 0 \\
\hline Words with [z] & 0 & 6 & 0 \\
\hline
\end{tabular}

The results show that Classical Arabic words are usually written with $\langle$ th $>$. Moreover, people write the letter dhal as they pronounce it, i.e., when it is pronounced [d] they write $\langle\mathrm{d}\rangle$ and when it is pronounced $[\mathrm{z}]$, they write $\langle\mathrm{z}\rangle$.

\subsubsection{Thaa' and dhal in Israel/ Palestine}

\footnotetext{
${ }^{24}$ The thaa' here is geminated, therefore, it is written $\langle\mathrm{ss}\rangle$ instead of $\langle\mathrm{s}\rangle$.

${ }^{25}$ This is because in urban dialects in Israel/Palestine the word $\langle\mathrm{mt} 2 \mathrm{ssir}\rangle$ is pronounced as $\langle\mathrm{mt} 2 \mathrm{ttir}\rangle$.
} 
Thaa' in Israel/Palestine is generally pronounced $[\Theta]$ in rural areas and [t]in urban areas, and rarely [s]. I noticed that [s] is used with the proper noun [suraja] and the word ['sbit] ("prove") in speech. However, because Facebook is a public CMC, sometimes rural people, especially females, write urban forms, particularly when interacting with people from the city. Consider the following tables:

Table 42 A: thaa' in Israel/Palestine: urban people chatting with rural and urban people

\begin{tabular}{|l|l|l|l|}
\hline & $\langle$ th $\rangle$ & $\langle\mathrm{t}\rangle$ & $\langle\mathrm{t}\rangle \%$ \\
\hline Males & 0 & 27 & $100 \%$ \\
\hline Females & 0 & 38 & $100 \%$ \\
\hline
\end{tabular}

Table 42 B: thaa' in Israel/Palestine: rural people chatting with other rural people

\begin{tabular}{|l|l|l|l|}
\hline & $\langle$ th $\rangle$ & $\langle\mathrm{t}\rangle$ & $\langle\mathrm{t}\rangle \%$ \\
\hline Males & 28 & 4 & $12.5 \%$ \\
\hline Females & 13 & 34 & $72.3 \%$ \\
\hline
\end{tabular}

Table 42 C: thaa' in Israel/Palestine: rural people chatting with urban people

\begin{tabular}{|l|l|l|l|}
\hline & $\langle$ th $\rangle$ & $\langle\mathrm{t}\rangle$ & $\langle\mathrm{t}\rangle \%$ \\
\hline Males & 23 & 11 & $32.4 \%$ \\
\hline Females & 4 & 29 & $87.9 \%$ \\
\hline
\end{tabular}

I do not have data relating to the spoken language of Israelis/Palestinians, so it is not clear to what extent their written usage corresponds to their spoken one. It may be that many would write $\langle\mathrm{t}\rangle$ more frequently than they would say $[\mathrm{t}]$, just as there are younger speakers who say [q] but write $\langle 2\rangle$. It is clear, however, that rural females write $\langle\mathrm{t}\rangle$ more than rural males do, and both write $\langle\mathrm{t}\rangle$ more when they are writing to urban people than when they are writing to other rural people.

Regarding dhal, it is written as $\langle\mathrm{d}\rangle$ or $\langle\mathrm{z}\rangle$ (according to the word) by urban speakers and as $<$ th $>$ by rural speakers, especially males. This is shown in Table 43:

Table 43: dhal is Israel/Palestine (Facebook data)

\begin{tabular}{|l|l|l|l|}
\hline & $\langle\mathrm{d}\rangle$ & $\langle\mathrm{z}\rangle$ & $\langle$ th $\rangle$ \\
\hline $\begin{array}{l}\text { Urban people } \\
\text { (males/females) }\end{array}$ & 9 & 3 & 0 \\
\hline Rural males & 3 & 1 & 6 \\
\hline Rural females & 6 & 4 & 2 \\
\hline
\end{tabular}

\subsection{Jeem}

The form $\langle\mathrm{j}\rangle$ is most frequently used to write jeem in Levantine EA.

\subsection{Jeem in Jordan, Lebanon and Israel/Palestine}


In Jordan, Jeem is pronounced [3] by Lebanese people, as well as urban Jordanians and Israelis/Palestinians. It is pronounced [dz] by rural people in Jordan and Israel/Palestine; ${ }^{26}$ however, it is usually written as $\langle\mathrm{j}\rangle$ and rarely as $\langle\mathrm{g}\rangle$. Consider the following table:

Table 44: Jeem

\begin{tabular}{|l|l|l|l|}
\hline & $\langle\mathrm{j}\rangle$ & $\langle\mathrm{g}\rangle$ & $\mathrm{N}$ \\
\hline Jordan & $87 \%$ & $13 \%$ & 117 \\
\hline Lebanon & $100 \%$ & $0 \%$ & 101 \\
\hline Israel/Palestine & $67 \%$ & $33 \%$ & 69 \\
\hline
\end{tabular}

\subsection{Sheen}

Sheen is normally written as <sh>except in Lebanon and Morocco where it is written as <ch> as in French rather than $\langle\mathrm{sh}\rangle$ as in English. In Jordan, young people are trying to avoid the digraph $\langle$ sh $\rangle$, preferring to use the monograph $\langle \$\rangle$ to represent sheen.

\subsection{Sheen in Jordan}

In Jordanian EA, sheen can be written as $\langle$ sh $\rangle$ or $\langle \$\rangle$. $\langle \$\rangle$ is an innovation that avoids the digraph $\langle\mathrm{sh}\rangle$. The "dollar" symbol is now used by youngsters in Jordan to denote $/ \mathrm{g} /$. Although this way of writing is still new and not used by many teenagers, it is still evidence that these youngsters are looking for both monographs and "cool" ways of writing. The process of turning a digraph into a monograph is common in history. The English letter $\langle\mathrm{x}\rangle$ was originally a combination of two Greek letters, that is, the Greeks combined the two letters for [k] and [s], and then Latin borrowed it as a single letter. Also umlauted letters in languages such as German and Swedish ( $\ddot{a} / \mathrm{o} / \ddot{\mathrm{u}} /)$ originated as writing an $\langle\mathrm{e}\rangle$ over the other letter, which eventually changed into two dots.

The data collected from teenagers in Irbid shows how widespread the $\langle \$\rangle$ is:

Table 45: sheen used by Irbidawi teenagers

\begin{tabular}{|l|l|l|}
\hline & $\langle\mathrm{sh}\rangle$ & $\langle \$\rangle$ \\
\hline Tokens & 105 & 44 \\
\hline Percentage & $70.5 \%$ & $29.5 \%$ \\
\hline
\end{tabular}

Moreover, I assessed whether this usage is related to the age of the writer. Hence, I divided my subjects into three age groups: younger than 16, 16-18, 19 and older. Consider the following table:

Table 46: sheen (Irbid): age differences

\begin{tabular}{|l|l|l|l|l|}
\hline & $\langle\mathrm{sh}\rangle$ & $\langle \$\rangle$ & Other & $\langle \$>\%$ \\
\hline 16 and younger & 27 & 34 & 0 & $55.7 \%$ \\
\hline
\end{tabular}

\footnotetext{
${ }^{26}$ In speech, however, females tend to pronounce the jeemas [3] and not as [dz], and males vice versa. This is
} because [3] is considered more prestigious (Al-Ali \&Arafa 2010:217). 


\begin{tabular}{|l|l|l|l|l|}
\hline $17-18$ & 38 & 10 & 0 & $20.8 \%$ \\
\hline 19 and older & 40 & 0 & 0 & $0 \%$ \\
\hline
\end{tabular}

We see here that $\langle \$\rangle$ is a new form whose use is restricted to people under the age of 19 . We will know whether this new letter will replace $<$ sh $>$ only after several years.

\subsection{Sheen in Lebanon}

The Lebanese are influenced by both the Anglophones and Francophones. However, the French language is more dominant in Lebanon than English. The letter sheen is written as <ch> or $<$ sh> by Lebanese EA users.

Table 47: sheen in Lebanon

\begin{tabular}{|l|l|l|}
\hline & $<\mathrm{sh}>$ & $<\mathrm{ch}>$ \\
\hline Tokens & 46 & 61 \\
\hline Percentages & $43 \%$ & $57 \%$ \\
\hline
\end{tabular}

Clearly, both forms are used, but $\langle\mathrm{ch}\rangle$ is used a little more than $\langle\mathrm{sh}\rangle$. However, there is a very strong pattern in terms of the religion of the user, as shown in Table 48:

Table 48: (Lebanon) differences in writing the sheen according to religion

\begin{tabular}{|l|l|l|}
\hline & $\langle\mathrm{sh}\rangle$ & $\langle\mathrm{ch}\rangle$ \\
\hline Muslims & 44 & 1 \\
\hline Christians & 2 & 60 \\
\hline
\end{tabular}

Usually, more Muslims attend schools that teach English, while Christians are more likely to attend schools that teach French as the second language, which accounts for the difference between the groups in terms of writing sheen.

\subsection{Grammatical Variables}

In the following section I will discuss two grammatical variables in EA, the definite article and negation.

\subsection{The Definite Article ${ }^{27}$ (/?al/)}

In this section, I examine how the definite article is written in different EAs. Before I present the results, I would like to give some information that is essential for understanding this section.

Arabic letters in general are divided into two groups: apical ("sun letters") and non-apical ("moon letters"). Before apical letters, the [1] of the definite article is assimilated to the

${ }^{27}$ I could find no difference in written forms among different age groups in any of the countries. 
following consonant, which is pronounced as a geminate (double letter). The apicals include dentals, alveolars, and postalveolars. Some of these apical letters are: ج, د, ض, ص, ط, ذ

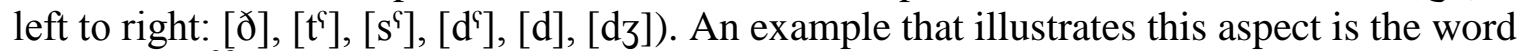
$\left[{ }^{2} \mathrm{~d} 3 \mathrm{~d} 3 \wedge \mathrm{b} \wedge 1\right]^{28}$ ("the mountain"). The definite article $\left\langle ا ٔ{ }^{2}>\right.$ al] is fully written in the Arabic script including the $\langle J\rangle[1]$; however, when pronounced, it is assimilated with the consonant that follows. ${ }^{29}$ Apical letters are traditionally called "sun letters" because the word "sun" in Arabic

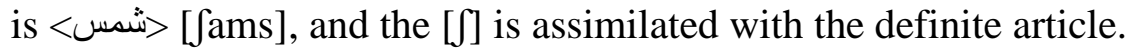

On the other hand, non-apical letters are the letters that do not assimilate with the definite article $\left\langle ا ٔ ل{ }^{30}\right.$ For instance, the word heart in Arabic is $\langle$ قلب [qalb]. The letter qaf $\langle$ ق> [q], is a non-apical letter, and when the definite article precedes this word it is pronounced without assimilation [al-qalb].

The most frequent definite articles used by EA users are <el $>$, <al $>$ and $\langle 1\rangle$; therefore, I am going to focus on these three forms. Before analyzing the three usages, it is important to understand that in spoken Arabic the most common pronunciation of the definite article is [el]; however, Bedouins pronounce it as [al], the classical Arabic pronunciation. In EA writing, the <al> has three usages: the first is with words from classical Arabic, e.g., <kamelal2wsaf> ("someone who is ideal or perfect"); the second is when the definite article is preceded by the preposition [Sala] ("about,"“to") and it is assimilated with the definite article and written <3al>, for instance, <3almdrasi> ("to school"); and lastly, some people, with no clear pattern, use $\langle\mathrm{al}\rangle$, despite the fact that they pronounce it [el]. The two other usages, $\langle 1\rangle$ and $\langle\mathrm{el}\rangle \mid\langle\mathrm{il}\rangle$, are used interchangeably.

\subsubsection{Definite article in general}

In general, the definite article in the Levant is always separated when it comes after a preposition, before a word in English it is separated the great majority of time, while before proper nouns it is separated barely half the time. See the following table:

Table 49: The Definite article

\begin{tabular}{|l|l|l|l|l|}
\hline & Preposition & English word & Proper noun & Other \\
\hline Prefixed & 0 & 9 & 20 & 81 \\
\hline Separated & 74 & 28 & 24 & 138 \\
\hline
\end{tabular}

In general, the $<1>$ is almost always retained, even for apical letters. Moreover, the article is usually written as separate with prepositions, English words, and proper names in Lebanon. In Israel/Palestine and Jordan, the article is usually prefixed with proper nouns. The relative frequency of prefixing and separating varies from dialect to dialect. Lebanon is much more extreme than the others in terms of favoring separating in other situations as shown in Table 50:

Table 50: What is most common, separation or prefixing?

\footnotetext{
${ }^{28}$ The [dz] is geminated.

${ }^{29}$ See: Heath(2002:169)

${ }^{30}$ The names "moon" letters and "sun" letters in Arabic were chosen in order to make it easier for learners (also for native speaker children) to remember.
} 


\begin{tabular}{|l|l|l|l|}
\hline Country & Prefixed & Separated & Prefixed \% \\
\hline Israel/Palestine & 40 & 48 & $45.5 \%$ \\
\hline Jordan & 27 & 34 & $44 \%$ \\
\hline Lebanon & 14 & 56 & $20 \%$ \\
\hline
\end{tabular}

\subsection{Negation}

In this subsection, I am going to examine negation and the different negation particles used in different countries in EA writing.

\subsubsection{Jordan}

In Jordan, several negation particles are used: the prefixes, $m a, m u, m i s h$, and the suffix $<\mathrm{sh}\rangle$. The prefix $<m a>$ and the suffix $<\mathrm{sh}>$ are used to negate verbs and prepositions, such as $<$ mafi $>$ or <fish> ("there is not/are not"), the latter being more prevalent than the former. The prefixes $m u$ and mish are used before nouns, adverbs, and adjectives, for instance, <mo 5jla> ("not embarrassed"), <molhdaraji> ("not that much"), etc.

In EA, the prefixes $m u$ (written $<\mathrm{mo}>$ ) and mish (written $<\mathrm{msh}>$ ) are always separated from the following words. However, although $m a(<m a>)$ is usually separated, sometimes it is prefixed to prepositions, as in $\langle$ mafi $>$. The suffix $<\mathrm{sh}>$ can never be separated. The following tables show the results:

Table 51: The prefixes $m a, m u, m i s h$ in Jordan

\begin{tabular}{|l|l|l|l|l|}
\hline & $\langle\mathrm{ma}\rangle$ & $\langle\mathrm{ma}\rangle+$ prep. & $\langle\mathrm{mo}\rangle$ & $\langle\mathrm{msh}\rangle$ \\
\hline Prefixed & 0 & 3 & 0 & 0 \\
\hline Separated & 56 & 0 & 23 & 34 \\
\hline
\end{tabular}

Table 52: The suffix <sh>in Jordan

\begin{tabular}{|l|l|}
\hline & $\langle\mathrm{sh}>$ \\
\hline Suffixed & 46 \\
\hline Separated & 0 \\
\hline
\end{tabular}

\subsubsection{Lebanon}

In the Lebanese dialect, there are two particles for negation that are used as prefixes, $m a$ and mish. The particle $m a$ is used to negate verbs and prepositions, e.g., <ma be2bal > ("I do not accept") and <mafi> ("there is not/are not"), while the particle mish is used with nouns, adjectives, and adverbs. 
In Lebanese EA, the negation prefixes are separated from the following word. Mish is written as $<$ mech $>$ in accordance with the norm in Lebanon. However, when $m a$ (written $\langle$ ma $>$ ) is followed by the preposition $f e$ they are joined together as in $\left\langle\right.$ mafi $>{ }^{31}$

Table 53: The negation particles ma and mish in Lebanon

\begin{tabular}{|l|l|l|l|}
\hline & $\langle\mathrm{ma}\rangle$ & $\langle\mathrm{ma}\rangle+$ prep. & $\langle$ mech $\rangle$ \\
\hline Prefixed & 0 & 2 & 0 \\
\hline Separated & 45 & 0 & 28 \\
\hline
\end{tabular}

\subsubsection{Israel/Palestine}

In Israel/Palestine, negation is expressed in several ways:

1. $M i s h^{32}+$ adjectives/nouns/adverbs/pronouns/verbs and possessive forms: [mifhilo], [mifana] ("not beautiful, not me").

2. The suffix $s h^{33}$ with $b$ - imperfect ${ }^{34}$ or with the preposition $f e$ ("there is/are"), e.g., [b3rifif], [bideef], [fif]("I do not know," "I do not want,"“there is not/are not"). The prefix $m a$ and the suffix $s h^{35}$ are used with verbs in the perfect and the imperfect, and also with the preposition $f e$ : [makaltif], [madarastif], [mabtisdarif], [mafif] ("I did not eat,"“I did not study,"“you cannot,"“there is not/are not").

Data are given in Table 54:

Table 54: Negation in Israel/Palestine

\begin{tabular}{|l|l|l|l|}
\hline & $\left\langle\mathrm{msh}>^{36}\right.$ & $\begin{array}{l}<\mathrm{ma} \ldots \mathrm{sh}>\text { (past } \\
\text { v.) }\end{array}$ & $<\mathrm{b} \ldots \mathrm{sh}>$ (present v.) \\
\hline Prefixed/ suffixed & 0 & 15 & 24 \\
\hline Separated & 11 & 0 & 0 \\
\hline
\end{tabular}

As can be seen, in Israeli/Palestinian EA, the negation particle $<\mathrm{msh}>$ is separated from the word that follows it; however, the prefixes $\langle$ ma $\rangle$ and $\langle b\rangle$ and the suffix $\langle s h\rangle$ are not separated but always attached to the word.

\subsection{Conclusion}

\footnotetext{
${ }^{31}$ Note that in Lebanon $m a$ is at the beginning of the word without the suffix $s h$ being added, unlike in Israel/Palestine where the negation prefixma comes with the suffix $s h$.

${ }^{32}$ Blanc (1953: 208) gives the forms mish and mush for Northern Palestinian villages. Bauer (1926:122) and Haddad (1927: 24) give the form mush.

${ }^{33}$ The negation particle [S] is characteristically Palestinian (Blanc 1953a: 210; Driver 1925: 197; Bauer 1926: 122; Haddad 1927: 42; Blau 1960: 195). However, this particle was not mentioned by Kapliwatzky (1968).

${ }^{34}$ For elaboration of the perfect and imperfect tenses, see Havelova (2000: 148-153).

${ }^{35}$ This type of negation, Elihay (1989:188) states, is used in Palestine, but is also known in Lebanon. According to Bergsträsser (1915: Map 21) and Driver (1925:196), this type of negation is characteristic of Palestine and partly of Lebanon.

${ }^{36}$ The vowel is omitted for the negator $<\mathrm{msh}>$ in Jordan and Israel/Palestine, but not in Lebanon.
} 
I open this Conclusion with a general summary of the results of my investigation of EA in the Levant, followed by a review of the local standards used in different places and the general trends that are spreading. Finally, I will discuss implications and directions for further research.

\subsubsection{Lebanon}

In general, the Lebanese do not use pharyngeals in speech, although sometimes males do. In EA they rarely express pharyngealizations, and when they do they use capitalization and not numerals.

Lebanese use $<\mathrm{h}>$ for $\hbar a a$ ', zero for 'ayin, <kh> for khaa', and <gh> for ghain in proper nouns; $\langle\mathrm{kh}\rangle$ is also used for khaa' in other words and not just proper nouns by those who are above 27 years of age. In EA, to denote ghain $\langle 3$ ' $\rangle$ is much more prevalent than $\langle 8\rangle$. People use $\langle 2\rangle$ for $q a f,\langle\mathrm{t}\rangle \mid\langle\mathrm{s}\rangle$ for thaa', and $\langle\mathrm{d}\rangle \mid\langle\mathrm{z}\rangle$ for dhal. They use the two forms $\langle\mathrm{ch}\rangle$ and $\langle\mathrm{sh}\rangle$ for sheen alternatively; the choice of usage seems to be based mainly on the writer's religion.

The definite article is separated when a preposition precedes it. Negation, i.e., the particles $m a$, and mech, are separated from the words that follow.

\subsubsection{Israel/Palestine}

Rural users of EA in Israel/Palestine tend not to write as they speak, especially when writing to strangers. Hence, they tend to use the standard form for qaf which is $\langle 2\rangle$. Furthermore, although the letter $k h a a^{\prime}$ used to be written as $\left\langle 7^{\prime}\right\rangle$, today $\langle 5\rangle$ is more prevalent and $\left\langle 7^{\prime}\right\rangle$ is dying out.

In proper nouns in this dialect, $<\mathrm{h}>$ is used for $\hbar a a^{\prime},<\mathrm{kh}>$ for $k h a a^{\prime},<\mathrm{gh}>$ for ghain, and zero for 'ayin; otherwise these sounds are written with $\langle 7\rangle,\langle 5\rangle \mid\langle 7$ ' $\rangle,\langle 3$ ' $\rangle$, and $\langle 3\rangle$, respectively.

The writing system in Israel/Palestine is very similar to that in Lebanon, other than that Lebanese Christians write <ch $>$ for sheen, and, at least according to the database, there seem to be more rural forms in Israel/Palestine, such as $\langle\mathrm{q}\rangle|\langle\mathrm{g}\rangle|\langle\mathrm{k}\rangle$ for $q a f$. Israelis/Palestinians also write $<2>$ for initial hamza much more frequently than do the Lebanese.

The definite article is always separated from the word when there is a preposition or the demonstrative article. The negation particle $m s h$ is usually separated from the succeeding word, but $m a . . . s h$ and $b \ldots s h$ are usually prefixed and suffixed, i.e., the $m a$ and $b$ are prefixed and the $s h$ is suffixed.

\subsubsection{Jordan}

Jordanian usage is a mixture of the Lebanese, Israeli/Palestinian and Egyptian, and the Gulf usages. Gender is very important in Jordan. For example, Jordanian males tend to use $\langle 9\rangle$ for $s^{\varsigma} a a d$ and $\langle 6\rangle$ for $t^{\uparrow} a a^{\prime}$ more than do females, who use $\langle s\rangle$ and $\langle t\rangle$ respectively. Moreover, Jordanians use $\langle 8\rangle$ for $q a f$, which means they never key-in $<8>$ for ghain as in Egypt, Israel/Palestine and Lebanon. On the other hand, Jordanians also use many features in the same way as Egyptians, Israelis/Palestinians and Lebanese: sometimes $\langle 2\rangle$ or $\langle\mathrm{q}\rangle$ is used for $q a f$, $<\mathrm{t}\rangle$ is used for thaa' or $t^{\uparrow} a a^{\prime},<\mathrm{s}>$ for $s^{\uparrow} a a d$, and the $\left\langle^{\prime}>\right.$ more often follows the number. 
Moreover, Jordanians never use $<\mathrm{g}>$ for jeem, while Israelis/Palestinians sometimes do, although rarely. According to my observations, since they commonly use $<\mathrm{g}>$ for $q a f$ Jordanians use $\langle\mathrm{j}\rangle$ for jeem more than $\langle\mathrm{g}\rangle$.

EA users in Jordan, in order to avoid digraphs, are starting to write $\langle \$\rangle$ instead of $\langle$ sh $\rangle$ to denote the sheen; only in Jordan is the $\langle \$\rangle$ used for sheen. Furthermore, as in the Gulf, Jordanians use the forms $\langle\mathrm{h}\rangle,\langle\mathrm{kh}\rangle,\langle\mathrm{a}\rangle$, and $\langle\mathrm{gh}\rangle$ in proper nouns with the letters $\hbar a a$, $k h a a$ ', 'ayin, and ghain, but $\langle 7\rangle,\langle 5\rangle,\langle 3\rangle$, and $\langle 3$ ' $\rangle \mid\left\langle{ }^{\prime} 3\right\rangle$ in other words.

In Jordan, the definite article is always separated from the word when there is a preposition and it is also separated when it precedes a word in English. With negation, $m a$, $m o$, $m s h$ are separated, whereas $s h$ is always written as a suffix.

\subsection{General trends}

It appears that Lebanon and Israel/Palestine can be called the $\langle 2\rangle$ area, defined according to the pronunciation of $q a f$, while Jordan is the $\langle 8\rangle \mid\langle\mathrm{g}\rangle$ area, and the $\langle 2\rangle$ area. The reason for this is that Jordan comprises two different societies, the Palestinian and the Jordanian (Bedouin). The different dialectal areas are defined by their standard dialect; for example, the glottal stop for qaf is the standard dialect in Israel/Palestine, because the urban dialect, owing to its prestige, is considered the local standard dialect. In this area, the urban forms $\langle\mathrm{t}\rangle,\langle\mathrm{d}\rangle$, and $\langle 2\rangle$ are more prevalent in the writing of rural teenagers than in their speech. Teenagers' concern for prestige on CMC is the main motivation for this type of standardization. They always strive to appear elegant and sophisticated, especially to the other sex. Consistent with several studies showing that women are usually the leaders of changes in speech (See Labov, 1982, 1991; Eckert \& McConnell-Ginet, 1992), female teenagers are the leaders of this trend.

Moreover, since the standard local/regional forms are the urban forms, this means that the forms are spreading from the cities to the villages, and that cities are dominating the villages. However, in some societies, such as that of the Bedouins, dialect and identity are bound together. An essential element of the Bedouin identity, especially now that they are no longer identified by their nomadic lifestyle, is speaking the Bedouin dialect. Hence, Bedouins who live in Jordan cannot easily write $<2>$ since on the one hand, they would be despised by others in their society for doing so and thereby denying their identity, and on the other, they would be mocked by non-Bedouins for trying to appear to be other than what they are. Therefore, they found a compromise in using the form $\langle 8\rangle$, which does not necessarily represent $\langle\mathrm{g}\rangle$, but might also represent $\langle\mathrm{q}>$, which is a moderate and respected form to use.

The general trend is that EA users write as they speak, but in some cases they are confused because it is not always clear to them how to write. There are four main reasons:

1.In some cases, the appearance of a standardized dialectal form, e.g., $<2>$, which is used by urban EA users in the Levant, causes a complication. One reason for standardization is the prestige factor, which particularly affects rural people, especially those who are younger than 28 years old. They are more affected by prestige when they write than when speak. For examples, for $q a f$ they may say $g$ and write $<2>$, or say $[\Theta]$ and write $\langle\mathrm{t}\rangle$.

2. Avoiding controversial forms: In Jordan, for example, $\langle 8\rangle$ is used by rural people and Bedouins in order to avoid the two extreme forms $\langle\mathrm{g}\rangle$ and $\langle 2\rangle$.

3. People who are over 28 years old frequently use the digraphs $\langle\mathrm{kh}\rangle$ and $\langle\mathrm{gh}\rangle$ for $k h a a$, 
and ghain. However, sometimes the letter that these forms denote is not obvious when one reads a word; for instance, the word[xirib] which is written as $\langle$ khrib $\rangle$ ("was broken down") can be read as [kahrib] ("make an electric shock"). Therefore, sometimes these people use $\langle\mathrm{kh}\rangle$, but when they notice such a problem in deciphering the word they use a monographic form such as $\langle 5\rangle$.

4. Writing conventions have not yet fully developed and therefore there is variation. Since when the older people started to write there were no conventions, this is more the case for older than younger people. It is also more true concerning some forms than othersfor example, much variation is seen in the usage of ghain and khaa' because there are no obvious single symbols to denote them.

Another trend is to eliminate digraphs. EA users prefer to use numerals rather than digraphs, the result of which is to avoid using forms such as $\langle\mathrm{gh}\rangle$ and $\langle\mathrm{sh}\rangle$; thus, ghain has begun to be written as $\langle 8\rangle$ in Egypt and Lebanon, while Jordanian EA users have started to write sheen as $\langle \$\rangle$. Moreover, there is a tendency to avoid forms with apostrophes, resulting in the emergence of the new form $\langle 8\rangle$ for $\langle 3$ ' $>$ to represent ghain in the Triangle area in Israel/ Palestine (see Garra, forthcoming). This form has also spread to Egypt and Lebanon. In Jordan, the form <4> is appearing instead of $\left\langle 3{ }^{\prime}\right\rangle$ (see 5.2.4.2). Another example of this is the gradual disappearance of the form $\langle 7$ ' $\rangle$ for $k h a a^{\prime}$ and its replacement by the form $\langle 5\rangle$.

\subsection{Implications}

More research should be conducted on the regional standards developing in different areas. Despite the fact that my research study revealed the situation in the Levant, there are other regional standards that I did not manage to ascertain. Further research should study the different writing systems used in EA, Arabic script, Latin script and Hebrew script (in Israel/Palestine) thoroughly, in order to discover how EA is written in different scripts. In addition, a comparison can be made between the Hebrew and the Latin scripts to assess in which one of the two scripts people use more digraphs or monographs. It is also important to assess which social group uses the different scripts. For instance, one might find that Bedouins and Druze in Israel use Hebrew script much more than other Muslims and Christians, in which case one should search for reasons why Bedouins and Druze use Hebrew script significantly more than Latin. One might check also the hypothesis that the older the person is the more likely he or she is to use Hebrew script. Technical reasons might also influence the choice of the script. For example, we can check the hypothesis that a person is more likely to use a script that can be keyed-in faster.

An additional important issue is "switching" in EA scripts or vocabulary. Research can also investigate when and why many people switch code when writing in EA. Many switch from Arabic script to English script, Arabic script to French script (in Lebanon and North Africa), Arabic script to Hebrew script, and so on. Moreover, people write two different languages in one script, e.g., writing Arabic in Latin script then a Hebrew word in Latin Script. Many social, emotional, or even technical factors might be behind this practice.

Another important and complementary component that should be considered is the research of vowels in EA writing, since it is integrally connected to the research that is conducted in this thesis. However, because of the arbitrariness and variation of vowel usage, it will constitute a time consuming and much more complicated study. In the research about vowels, different countries, ages, and perhaps genders should also be considered. The differences in vowel usage are related also to the type of education of the speaker. Those who speak French as a second 
language prefer $\langle\mathrm{i}\rangle,\langle\mathrm{u}\rangle$ and $\langle\mathrm{ou}\rangle$ (North African Arabs and Lebanese), while those who speak English as a second or foreign language tend to use $\langle\mathrm{e}\rangle$, and $\langle 0\rangle$. In addition to this, a comparison between the standardization of vowels versus consonants might be conducted to assess whether vowels or consonants are becoming standardized first.

In a nutshell, this type of research is endless for there is so much that needs to be investigated, always demanding more accurate and extensive research. Furthermore, the obstacles are many and varied. To add to all this, EA is not yet standardized and this is an ever-changing process; especially that EA is a phenomenon that might get more common in the future. 


\section{Bibliography}

Abdel- Jawad, H. (1981).Lexical and Phonological Variation in Spoken Arabic in Amman.Doctoral dissertation, University of Pennsylvania.

Al-Ali, M.N., \&Arafa, H. (2010). "An Experimental Sociolinguistic Study of Language Variation in Jordanian Arabic."The Buckingham Journal of Language and Linguistics3: 207-230.

Al-Tonsi, A. (1980).Egyptian colloquial Arabic: A structural review. Cairo: American University in Cairo.

Al-Wer, E. (2007). "The Formation of the Dialects of Amman.” In Al-Wer,E., D. Caubet, \& Watson, J. (eds.), Arabic in the City Issues in Dialect Contact and Language Variation. Routledge Arabic Linguistic Series.

Bauer, L. (1926). Das PalästinischeArabisch: Die Dialekte des Städters und des Fallachen. $4^{\text {th }}$ ed. Leipzig.

Bergsträsser,G. (1915).Sprachatlas von Syrien und Palästina.Lipzig.

Behnstedt, P. (1997). Sprachatlas von SyrienKartenband.HarrassowitzVerlag.

Bishir, K. (2000). Silmil- 's ${ }^{\varsigma}$ wat (Phonetics).Dar Ghareeblil- t'baaSawal- nashirwal-tawzeeSCairo.

Blanc, H. (1953). Studies in North Palestinian Arabic: Linguistic Inquiries among the Druzes of Western Galilee and Mt. Carmel. Oriental Notes and Studies, Israel Oriental Society, No. 4. Jerusalem.

Blau, J. (1960). Syntax des PalästinichenBauerdialektes von Bir-Zet.Walldorf Hessen.

Crystal, D. (2001). Language and the Internet. Cambridge: Cambridge University Press.

Cyberspeech. (1997, June 23, 1997). Time, 149, 23.

Danet, B. \& Herring, S. (2003). “Introduction: The Multilingual Internet."Journal of Computer-Mediated Communication, 9(1).

December, J. (1996).“What is Computer-mediated Communication?”From http://www.december.com/john/study/cmc/what.html

Driver, G. R. A. (1925).A Grammar of the Colloquial Arabic of Syria and Palestine. London.

Eckert, P. \& McConnell-Ginet, S. (1992). “Think Practically and Look Logically: Language and Gender as Community-Based Practice."Annual Review of Anthropology 21;461490.

Elihai, Y. (1989). Particularites de L'arabeParléPalestinién.Jerusalem Studies in Arabic and Islam 12. 186-198. 
Fischer, W. \& O. Jastrow (2000).Handbuch Der ArabischenDialekte. Translated by R. Talmon. Jerusalem: The Hebrew University Press.

Freha, A. (1989). Al-lahjatwaOsloobDirasatiha (The Dialects and the Methods of Studying them). Dar Aljeel: Beirut.

Garra, I. (2007). M.A Thesis. From a Dialect into a Language: The case of English and Arabic. University of Haifa, Israel.

Haddad, E.N. (1927). Arabischwiees in Palästinagesprochenwird. Jerusalem.

Havelová, A. (2000). Arabic Dialects of Nazareth: A Dialectological and Sociolinguistic Description. Doctoral dissertation. University of Haifa, Israel.

Ibrahim, M. H. (1986). "Standard and Prestige Language: A Problem in Arabic Sociolinguistics."Anthropological Linguistics, 28 (1): 115-126.

Kapliwatzky. J. (1968). Colloquial Arabic. Rubin Mass, Jerusalem.

Labov, W. (1963) “The social Motivation of a Sound Change.”Word 19: 273-309; = Labov (1972a: ch.1),

. (1966) The Social Stratification of English in New York City. Washington DC: Center for Applied Linguistics,

. (1972a) Sociolinguistic Patterns. Oxford: Blackwell, . (1972b) Language in the Inner City. Oxford: Blackwell,

. (1973) “The Boundaries of Words and Their Meanings.”In C-J. Baily and R. Shuy, eds. New Ways of Analyzing Variation in English. Washington: Georgetown University Press,

. (1982). "Building on Empirical Foundations: Perspectives in Historical Linguistics." In Perspectives in Arabic Linguistics IV,

. (1991). "The Intersection of Sex and Social Class in the Course of Linguistic Change." Language Variation and Change 2:205-254.

Levin, A. (1994). "Sibawayhi's Attitude to Spoken Language." Jerusalem Studies in Arabic and Islam, 17: 204-243.

Liu, J. (2011). "Deviant writing and youth identity: Representation of dialects with Chinese characters on the internet." In Chinese Language and Discourse 2 (1): iii, 152 (pp. 58-79). John Benjamins Publishing Co.

Nishimura, Y. (2003). "Linguistic Innovations and Interactional Features of Casual Online Communication in Japanese.’'In Journal of Computer Mediated Communication 9(1).

Ornan, U.(2003). "Latin conversion of Hebrew: Grammatical, full and deficient."In Hebrew Studies, 44, 185-202.

Palfreyman, D. \& Al- Khalil, M. (2003).“A Funky Language for Teenzz to use: Representing Gulf Arabic in instant Messaging.’In Journal of Computer Communicated Communication.9 (1). 
Palva, H. (1984). "A General Classification for the Arabic Dialects Spoken in Palestine and Transjordan."StudiaOrientalia, 55: 359-376.

Pettersson, B. (1999). 'Who is Civilizing Who(m)? The Function of Naivety and the Criticism of Huckleberry Finn-a Multidimensional Approach.' In Taavitsainen, I., Melchers, G.,\&Pahta, P. 9eds.) Writing in Nonstandard English. John Benjamins Publishing Co.

Poussa, P. (1999). 'Dickens as Sociolinguist: Dialect in David Copperfield.' In Taavitsainen, I. Melchers, G., \&Pahta, P. (eds.), Writing in Nonstandard English. John Benjamins Publishing Co.

Romiszowski, A. \& Mason, R. (2004). "Computer-Mediated Communication," in Handbook of Research for Educational Communications and Technology, ed. David H. Jonassen (Mahwah, NJ: Lawrence Erlbaum, 2004), pp. 397-431; and Stefan Hrastinski and Christina Keller, "Computer-Mediated Communication in Education: A Review of Recent Research," Educational Media International, vol. 4, no. 1 (March 2007), pp. 61-77. Retrieved October 27, 2011 from: http://www.aect.org/edtech/15.pdf

Warschauer, M., El Said, G.R., \&Zohry, A. (2002)."Language Choice Online: Globalization and Identity in Egypt. "Journal of Computer Mediated Communication, 7(4).

Yaghan, M. A. (2008).“Arabizi: A Contemporary Style of Arabic Slang.” Retrieved October 14,2011

from:http://www.mitpressjournals.org/doi/abs/10.1162/desi.2008.24.2.39?journalCode $=$ desi

http://en.wikipedia.org/wiki/History_of_the_Arabic_alphabet. Retrieved October 15, 2011.

http://en.wikipedia.org/wiki/History_of_the_Greek_alphabet. Retrieved October 15, 2011.

http://www.wisegeek.com/what-is-facebook.htm.

*Dua'a Abu Elhij'a is a Fulbright Scholar and Ph.D candidate in the department of linguistics at Indiana University Bloomington. She holds an M.A. in Linguistics from the University of Haifa, Israel, and her article is based upon her M.A. research and thesis. 